\title{
Criptógamos do Parque Estadual das Fontes do Ipiranga, São Paulo, SP. Algae, 46: Bacillariophyceae (Bacillariaceae)
}

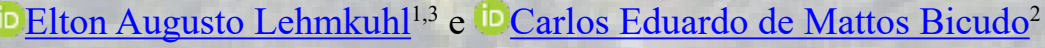

Como citar: Lehmkuhl, E.A. \& Bicudo, C.E.M. 2021. Criptógamos do Parque Estadual das Fontes do Ipiranga, São Paulo, SP. Algae, 46: Bacillariophyceae (Bacillariaceae). Hoehnea 48: e632020. https://doi.org/10.1590/2236-8906-63/2020

\begin{abstract}
Cryptogams of the Parque Estadual das Fontes do Ipiranga, São Paulo, SP. Algae, 46: Bacillariophyceae (Bacillariaceae). Survey was carried out of family Bacillariaceae (Bacillariophyceae) in the Parque Estadual das Fontes do Ipiranga, São Paulo, southeast Brazil, based on 28 samples. Analysis of specimens from the morphological point of view was made utilizing light microscope after oxidation and preparation of permanent slides. Four genera, 27 species and three varieties that are not the typical of their respective species were identified, from which nine are new registers for the State São Paulo [Nitzschia acicularis Hustedt, N. acidoclinata Lange-Bertalot, N. clausii Hantzsch, N. dissipata (Kützing) Rabenhorst, N. intermedia Hantzsch, N. palea (Kützing) W. Smith var. tenuirostris Grunow, N. subacicularis Hustedt, Tryblionella debilis Arnott ex O'Meara, and T. victoriae Grunow], and two are new records for the Brazilian territory [Grunowia solgensis (CleveEuler) Aboal and N. dissipata (Kützing) Rabenhorst var. borneensis Kützing]. Each identification was based on population samples, is presented by their morphological description and measurements, and is illustrated by photomicrographs.
\end{abstract}

Keywords: Brazil, diatoms, floristic survey, Grunowia, Hantzschia, Nitzschia, taxonomy, Tryblionella

RESUMO - Criptógamos do Parque Estadual das Fontes do Ipiranga, São Paulo, SP. Algae 46: Bacillariophyceae (Bacillariaceae). O levantamento florístico da família Bacillariaceae (Bacillariophyceae) foi realizado para a área do Parque Estadual das Fontes do Ipiranga, São Paulo, Brasil, com base em 28 unidades amostrais. O exame do material do ponto de vista morfológico foi realizado ao microscópio óptico após oxidação e confecção de lâminas permanentes. Quatro gêneros, 27 espécies e três variedades que não são as típicas de suas respectivas espécies foram identificados. Nove desses táxons foram registrados pioneiramente para o Estado de São Paulo [Nitzschia acicularis Hustedt, N. acidoclinata Lange-Bertalot, $N$. clausii Hantzsch, $N$. dissipata (Kützing) Rabenhorst, $N$. intermedia Hantzsch, $N$. palea (Kützing) W. Smith var. tenuirostris Grunow, N. subacicularis Hustedt, Tryblionella debilis Arnott ex O’Meara e T. victoriae Grunow] e dois para o Brasil [Grunowia solgensis (Cleve-Euler) Aboal e $N$. dissipata (Kützing) Rabenhorst var. borneensis Kützing]. Todo material foi identificado com base em amostras populacionais, descrito através de suas características morfológicas e medidas e ilustrado por fotomicrografias.

Palavras-chave: Brasil, diatomáceas, Grunowia, Hantzschia, levantamento florístico, Nitzschia, taxonomia, Tryblionella

\section{Introdução}

A família Bacillariaceae Ehrenberg pertence à classe Bacillariophyceae e compreende 18 gêneros, dos quais Nitzschia Hassal é o mais rico em espécies (aproximadamente 828 espécies), seguido por Hantzschia Grunow (aprox. 90 espécies) e Denticula Kützing (aprox. 30 espécies), conforme o AlgaeBase (Guiry \& Guiry 2020). Os representantes desta família são característicos por possuirem o canal da rafe localizado marginal ou submarginalmente e sustentado por fíbulas que podem ser observadas ao microscópio óptico como espessamentos silíceos transversais intercalados com as estrias da face valvar. As frústulas destes indivíduos possuem formato normalmente alongado e simetria apical. A família foi estudada por Mann (1978) quando ainda era chamada Nitzschiaceae, hoje sinônimo de Bacillariaceae (Kociolek et al. 2020).
Os trabalhos que ilustram e descrevem a morfologia das espécies da família em ambientes de água doce no Brasil estão concentrados na região sul do país (Garcia-Baptista 1993, Bes \& Torgan 2008, 2010a, 2010b, Cavalcante et al. 2013 e Bertolli et al. 2016, 2019). Bacillariaceae é um grupo taxonômico presente em amostras de ambientes brasileiros que vão desde águas marinhas, manguezais até a água doce, onde vivem como plânctôn, perifíton e nos sedimentos (Round et al. 1990), mas, ainda não há uma contribuição publicada tratando exclusivamente da família para as águas doces das demais regiões do Brasil.

A diversidade das Bacillariophyta do Parque Estadual das Fontes do Ipiranga é atualmente conhecida pelos trabalhos de Morandi et al. (2006) que estudaram as algas da classe Coscinodiscophyceae, Rocha \& Bicudo (2008) da família Pinnulariaceae, Marquardt \& Bicudo (2014) a ordem Cymbellales, Ferreira \& Bicudo (2017) da ordem Surirellales e Morais et al. (2019) do gênero Epithemia.

1. Universidade Federal do Amazonas, Estrada Parintins-Macurany, 1805, 69152-240 Parintins, AM, Brasil

2. Instituto de Botânica, Núcleo de Pesquisa em Ecologia, Avenida Miguel Estéfano, 3687, 04301-902 São Paulo, SP, Brasil

3. Autor para correspondência: eltonlh@hotmail.com 
Sobre a família Bacillariaceae constam algumas contribuições em artigos de cunho ecológico que, entretanto, não incluem descrição nem ilustração do material identificado. Assim, o objetivo do presente trabalho é conhecer a diversidade taxonômica das Bacillariaceae ocorrentes no PEFI, documentando-as com descrições morfológicas e fotomicrografias.

\section{Material e Métodos}

A área abrangida por este trabalho é a do PEFI, Parque Estadual das Fontes do Ipiranga situado na região sul do Município de São Paulo, onde abrange a área de 526,38 ha a uma altitude entre $770 \mathrm{~m}$ e $825 \mathrm{~m}$ (Melhem et al. 1981). O Parque abriga 24 nascentes situadas na malha urbana da cidade de São Paulo, em uma área que desde 1893 foi destinada a proteger a fauna e a flora da bacia do riacho Ipiranga (Morais et al. 2019).
Foram analisadas 28 unidades amostrais (tabela 1) pertencentes ao acervo do Herbário Científico do Estado "Maria Eneyda P. Kauffmann Fidalgo" (SP) do Instituto de Botânica da Secretaria de Infraestrutura e Meio Ambiente do Estado de São Paulo. A coleta do material do plâncton foi feita com auxílio de uma rede cônica confeccionada com tecido de náilon malha de $25 \mu \mathrm{m}$ de abertura; e as do perifiton pela raspagem manual de diferentes substratos submersos. Os métodos de fixação e preservação dos materiais amostrados do plâncton e do perifiton foram os mesmos empregados nos trabalhos anteriores sobre diatomáceas desta série (Marquardt \& Bicudo 2014, Ferreira \& Bicudo 2017, Morais et al. 2019). Todo o material foi preparado para estudo conforme o método de Simonsen (1974) modificado por Moreira-Filho \& Valente-Moreira (1981), que utiliza $\mathrm{K}_{2} \mathrm{MnO}_{4}$ e $\mathrm{HCl}$ para remoção da matéria orgânica. Nas amostras mais recentes, coletadas a partir de 2011, foi empregado o método proposto pela Comissão Europeia para

Tabela 1. Informações sobre as unidades amostrais estudadas no Parque Estadual das Fontes do Ipiranga, São Paulo, SP, Brasil. Table 1. Information about the sampling units studied in the Parque Estadual das Fontes do Ipiranga, São Paulo, SP, Brazil.

\begin{tabular}{|c|c|c|c|c|}
\hline Local de coleta & $\begin{array}{l}\text { Acesso no } \\
\text { Herbário }\end{array}$ & Hábito & $\begin{array}{c}\text { Data da } \\
\text { coleta }\end{array}$ & Coletores \\
\hline Hidrofitotério & SP255745 & perifíton & $18 / 07 / 1991$ & D.C. Bicudo, T.A.V. Ludwig \& D.M. Figueiredo \\
\hline Lago dos Bugios & SP255747 & perifíton & $18 / 07 / 1991$ & D.C. Bicudo, T.A.V. Ludwig \& D.M. Figueiredo \\
\hline Lago dos Bugios & SP255748 & fitoplâncton & $18 / 07 / 1991$ & D.C. Bicudo, T.A.V. Ludwig \& D.M. Figueiredo \\
\hline Córrego Pirarungáua & SP255749 & perifíton & $18 / 07 / 1991$ & D.C. Bicudo, T.A.V. Ludwig \& D.M. Figueiredo \\
\hline Córrego Pirarungáua & SP255750 & fitoplâncton & $18 / 07 / 1991$ & D.C. Bicudo, T.A.V. Ludwig \& D.M. Figueiredo \\
\hline Lago das Garças & SP255751 & perifíton & $18 / 07 / 1991$ & D.C. Bicudo, T.A.V. Ludwig \& D.M. Figueiredo \\
\hline Lago das Garças & SP255752 & fitoplâncton & 19/07/1991 & D.C. Bicudo, T.A.V. Ludwig \& D.M. Figueiredo \\
\hline Lago das Ninfeias & SP294899 & perifíton & 07/11/1996 & D.C. Bicudo \& L.L. Morandi \\
\hline Lago das Ninfeias & SP294900 & fitoplâncton & 07/11/1996 & D.C. Bicudo \& L.L. Morandi \\
\hline Lago dos Bugios & SP294901 & perifiton & $07 / 11 / 1996$ & D.C. Bicudo \& L.L. Morandi \\
\hline Lago dos Bugios & SP294902 & fitoplâncton & 07/11/1996 & D.C. Bicudo \& L.L. Morandi \\
\hline Hidrofitotério & SP294903 & perifíton & $07 / 11 / 1996$ & D.C. Bicudo \& L.L. Morandi \\
\hline Lago das Garças & SP294904 & perifíton & $14 / 01 / 1997$ & D.C. Bicudo \& L.L. Morandi \\
\hline Lago das Garças & SP294905 & fitoplâncton & $14 / 01 / 1997$ & D.C. Bicudo \& L.L. Morandi \\
\hline Lago do IAG & SP294906 & perifíton & $15 / 01 / 1997$ & D.C. Bicudo \& L.L. Morandi \\
\hline Lago do IAG & SP294907 & fitoplâncton & $15 / 01 / 1997$ & D.C. Bicudo \& L.L. Morandi \\
\hline Brejo do Lago & SP294908 & metafiton & $15 / 01 / 1997$ & D.C. Bicudo \& L.L. Morandi \\
\hline Lago do Monjolo & SP294909 & perifíton & 01/03/1997 & D.C. Bicudo \& L.L. Morandi \\
\hline Hidrofitotério & SP427341 & perifíton & $07 / 06 / 2011$ & P.D.A. Silva, G.C. Marquardt, S.W. Ribeiro \& B. Pelegrini \\
\hline Hidrofitotério & SP427342 & perifíton & $07 / 06 / 2011$ & P.D.A. Silva, G.C. Marquardt, S.W. Ribeiro \& B. Pelegrini \\
\hline Hidrofitotério & SP427343 & epifíton & $07 / 06 / 2011$ & P.D.A. Silva, G.C. Marquardt, S.W. Ribeiro \& B. Pelegrini \\
\hline $\begin{array}{l}\text { Sobre musgos e } \\
\text { tronco de árvore }\end{array}$ & SP427344 & perifiton & $07 / 06 / 2011$ & P.D.A. Silva, G.C. Marquardt, S.W. Ribeiro \& B. Pelegrini \\
\hline Lago das Ninfeias & SP469315 & fitoplâncton & $24 / 09 / 2014$ & L.F. Costa \& D.C. Bicudo \\
\hline Lago das Ninfeias & SP469316 & fitoplâncton & $24 / 09 / 2014$ & L.F. Costa \& D.C. Bicudo \\
\hline Lago das Ninfeias & SP469317 & perifiton & $24 / 09 / 2014$ & L.F. Costa \& D.C. Bicudo \\
\hline $\begin{array}{l}\text { Sobre musgos e } \\
\text { tronco de árvore }\end{array}$ & SP469318 & perifiton & $07 / 06 / 2011$ & L.F. Costa \& D.C. Bicudo \\
\hline Lago das Ninfeias & SP469576 & sedimentos & $24 / 10 / 2014$ & L.F. Costa \& D.C. Bicudo \\
\hline Hidrofitotério & SP469783 & fitoplâncton & $12 / 04 / 2017$ & S.A. Oliveira, K.S. Morais \& C.E.M. Bicudo \\
\hline
\end{tabular}


Padronização (ECS, "European Committee for Standartization" 2003) em que o $\mathrm{K}_{2} \mathrm{MnO}_{4}$ foi substituído pelo $\mathrm{H}_{2} \mathrm{O}_{2}$ e o material foi levado à temperatura de $80^{\circ} \mathrm{C} \mathrm{em}$ blocos digestores. Naphrax (I.R. 1,74), Hyrax (I.R. 1,67) e Zyrax (I.R. 1,7) foram os meios de inclusão utilizados para a confecção das lâminas permanentes.

As análises taxonômicas foram baseadas em amostras populacionais. As medidas foram tomadas dos eixos apical (comprimento) e transapical (largura) e a contagem, do número de estrias, fíbulas e aréolas foi providenciada de intervalos lineares de $10 \mu \mathrm{m}$. As medidas do comprimento do eixo apical e da largura máxima do eixo transapical foram obtidas diretamente das imagens produzidas pela câmera fotográfica acoplada ao microscópio.

Para identificação dos materiais foram utilizados trabalhos clássicos (ex. Krammer \& Lange-Bertalot 1988, Round et al. 1990) e recentes do tipo flora, monografia e revisão (ex. Bes \& Torgan 2010a, 2010b), bem como de outros que incluíssem materiais possivelmente relacionados. As bibliografias utilizadas para confirmação dos primeiros registros para o Brasil e estado de São Paulo foram artigos publicados em periódicos, apenas dos quais que apresentaram descrições e/ou ilustrações claras o suficientes para a verificação de caracteres diferenciadores dos táxons. Para tanto, listas de espécies em artigos de cunho ecológico, teses e dissertações não foram considerados.O enquadramento sistemático dos táxons no presente trabalho foi baseado em Medlin \& Kaczmarska (2004) para as categorias supraordinais e Round et al. (1990) para as subordinais.

\section{Resultados e Discussão}

Divisão Bacillariophyta Haeckel 1878 (= Diatomea Dumortier 1821 in Adl et al. 2005)

Subdivisão Bacillariophytina Medlin \& Kaczmarska 2004

Classe Bacillariophyceae Haeckel 1878 emend. Medlin

\& Kaczmarska 2004

Subclasse Bacillariophycideae D.G. Mann in Round et al. 1990

Ordem Bacillariales D.G. Mann in Round et al. 1990

Família Bacillariaceae Ehrenberg 1831

Grunowia Rabenhorst

Hantzschia Grunow

Nitzschia Hassal

Tryblionella W. Smith

As identificações com os nomes precedidos por um asterisco (*) têm, presentemente, seu primeiro registro para o Estado de São Paulo e os marcados com dois asteriscos (**) para o Brasil.

** Grunowia solgensis (Cleve-Euler) Aboal, Diatom Monographs 4: 467. 2003 三Nitzschia solgensis CleveEuler, Kongliga Svenska Vetenskaps-Akademiens Handlingar: sér. 4, 3(3): 67, fig. 1451c-d. 1952.

Figuras 1-11

Frústulas simétricas nos planos lateral e apical; valvas lanceoladas, ápices simétricos, sub-rostrados a subcaptados; estrias unisseriadas, paralelas no centro da valva, sutilmente inclinadas para os ápices, inconspícuas em alguns exemplares; aréolas circulares a elípticas, inconspícuas em alguns exemplares; canal da rafe marginal, fíbulas mais ou menos regularmente distribuídas, impossível distinguir as centrais pelo maior espaçamento; fíbulas marcadamente longas, podendo alcançar a região central da face valvar, algumas fíbulas unidas por espessamentos de sílica na face valvar; em alguns exemplares é possível visualizar, com mudanças de foco do microscópio, uma região mais clara na face valvar junto às fíbulas; medidas: eixo apical 8,5-26 $\mu \mathrm{m}$, eixo transapical 2,5-4,3 $\mu \mathrm{m}, 5-8$ fíbulas em $10 \mu \mathrm{m}, 17-$ 26 estrias em $10 \mu \mathrm{m}, 15-24$ aréolas em $10 \mu \mathrm{m}$.

Material examinado: BRASIL. São Paulo: São Paulo, Parque Estadual das Fontes do Ipiranga, Jardim Botânico, Lago das Garças, 18-VII-1991, D.C. Bicudo, T.A.V. Ludwig \& D.M. Figueiredo (SP255751); hidrofitotério, 07-XI-1996, D.C. Bicudo \& L.L. Morandi (SP294903); 12-IV-2017, S.A. Oliveira, K.S. Morais \& C.E.M. Bicudo (SP469783); 07-VI-2011, P.D.A. Silva, G.C. Marquardt, S.W. Ribeiro \& B. Pelegrini (SP427341, SP427342, SP427343); material sobre musgos e tronco de árvore, 07-VI-2011, P.D.A. Silva, G.C. Marquardt, S.W. Ribeiro \& B. Pelegrini (SP427344).

Hantzschia amphioxys (Ehrenberg) Grunow in Cleve \& Grunow, Beiträge zur Kenntniss der arctischen Diatomeen 17(2): 103, pl. 7, fig. 8. $1880 \equiv$ Eunotia amphioxys Ehrenberg, Abhandlungen der Königlichen Akademie der Wissenschaften zu Berlin 1843: 413, pl. 1/1, fig. 26, pl. 1/4, fig. 6. 1843 .

Figuras 12-16

Frústulas dorsiventrais, margem dorsal linear a mais ou menos convexa, margem ventral côncava; canais da rafe fortemente excêntricos, situados nas margens do mesmo lado da valva (simetria hantzschioide); ápices capitados; estrias paralelas por toda valva, as centrais podem aparecer mais espaçadas e grossas; em alguns exemplares é possível visualizar a falha de Voigt; fíbulas retangulares, distribuídas de forma regular, interrompidas na região central, onde é possível ver o nódulo central; aréolas raramente discerníveis ao microscópio óptico; medidas: eixo apical 21-61 $\mu \mathrm{m}$, eixo transapical 5-9,5 $\mu \mathrm{m}, 4-10$ fíbulas em $10 \mu \mathrm{m}, 16-31$ estrias em $10 \mu \mathrm{m}$.

Material examinado: BRASIL. São Paulo: São Paulo, Parque Estadual das Fontes do Ipiranga, Jardim Botânico, hidrofitotério, 07-VI-2011, P.D.A. Silva, G.C. Marquardt, S.W. Ribeiro \& B. Pelegrini (SP427341, SP427342, SP427343); 18-VII-1991, D.C. Bicudo, T.A.V.Ludwig \& D.M. Figueiredo (SP255745); Lago dos Bugios, 18-VII-1991, D.C. Bicudo, T.A.V. Ludwig \& D.M. Figueiredo (SP255747); Lago das Garças, 18-VII-1991, D.C. Bicudo, T.A.V. Ludwig \& D.M. Figueiredo (SP255751); Lago das Ninfeias, sedimentos, 24X-2014, L.F. Costa \& D.C. Bicudo (SP469576).

\section{Hantzschia sp.}

Figura 17

Frústulas dorsiventrais, margem dorsal mais ou menos convexa, margem ventral côncava; canais da rafe marginais, todos na mesma margem das valvas (simetria hantzschioide); ápices rostrados; estrias paralelas, as centrais mais espaçadas que as demais, as mais próximas dos ápices curvadas; fíbulas distribuídas irregularmente, com formato retangular e algumas são mais largas; 
fíbulas centrais mais espaçadas que as demais; aréolas não discerníveis; medidas: eixo apical ca. $72 \mu \mathrm{m}$, eixo transapical ca. $14 \mu \mathrm{m}, 4-7$ fíbulas em $10 \mu \mathrm{m}$, ca. 19 estrias em $10 \mu \mathrm{m}$.

Material examinado: BRASIL. São Paulo: São Paulo, Parque Estadual das Fontes do Ipiranga, Jardim Botânico, hidrofitotério, 07-VI-2011, P.D.A. Silva, G.C. Marquardt, S.W. Ribeiro \& B. Pelegrini (SP427341).

A espécie que mais se aproxima morfologicamente do presente material do PEFI é H. amphioxys (Ehrenberg) Grunow, mas difere por apresentar eixos apical e transapical mais longos e ápices rostrados. É necessário examinar mais material deste tipo para conseguir uma perfeita identificação taxonômica. Existe também a possibilidade de se tratar de uma espécie ainda não descrita para a Ciência.
* Nitzschia acicularis (Kützing) W. Smith, Synopsis of British Diatomaceae 1: 43, pl. 15, fig. 122. $1853 \equiv$ Synedra acicularis Kützing, Die Kielselschaligen Bacillarien oder Diatomeen. 63, pl. 4, fig. 3. 1844.

Figuras 18-19

Frústulas simétricas nos planos lateral e apical; valvas lineares, ápices bastante protraídos, estreitos; estrias e aréolas inconspícuas; canal da rafe marginal, fíbulas pequenas distribuídas regularmente, curtas, sem distinção das centrais; medidas: eixo apical 42-57,5 $\mu \mathrm{m}$, eixo transapical 2,7-3,2 $\mu \mathrm{m}, 14-20$ fíbulas em $10 \mu \mathrm{m}$.

Material examinado: BRASIL. São Paulo: São Paulo, Parque Estadual das Fontes do Ipiranga, Jardim Botânico, Lago das Garças, 18-VII-1991, D.C. Bicudo, T.A.V. Ludwig \& D.M. Figueiredo (SP255751).
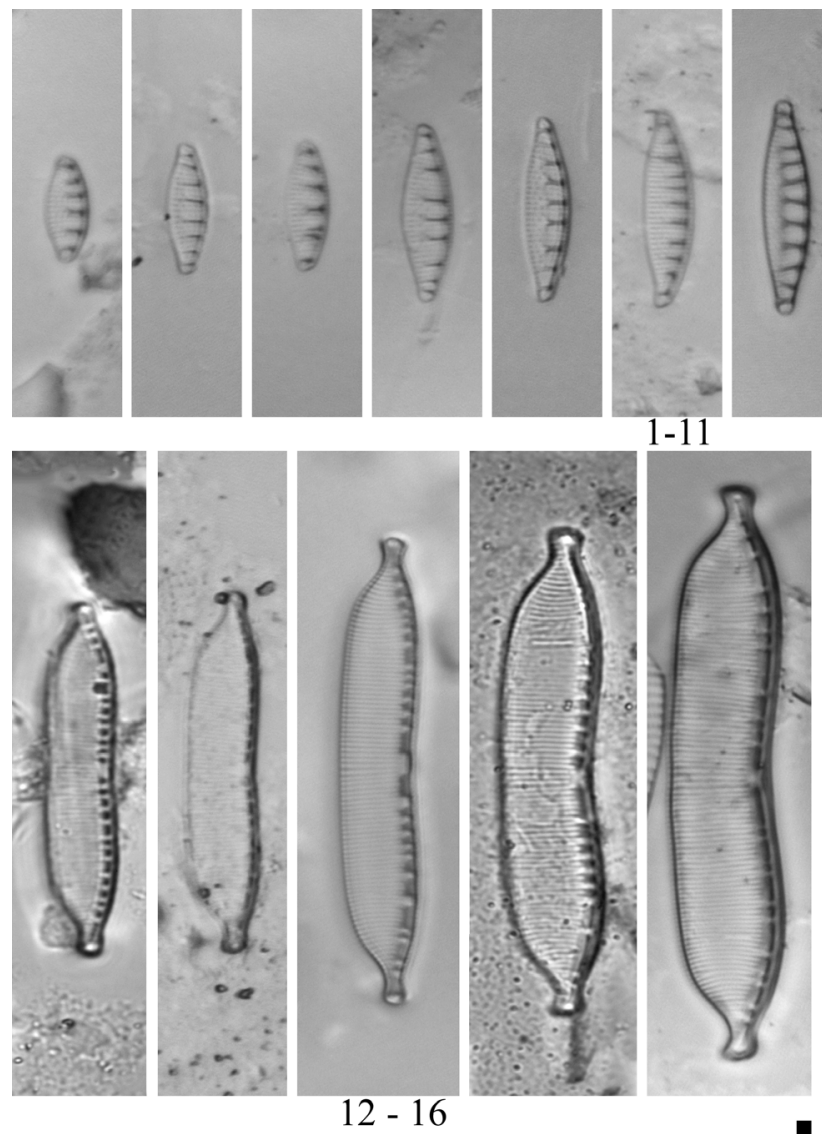
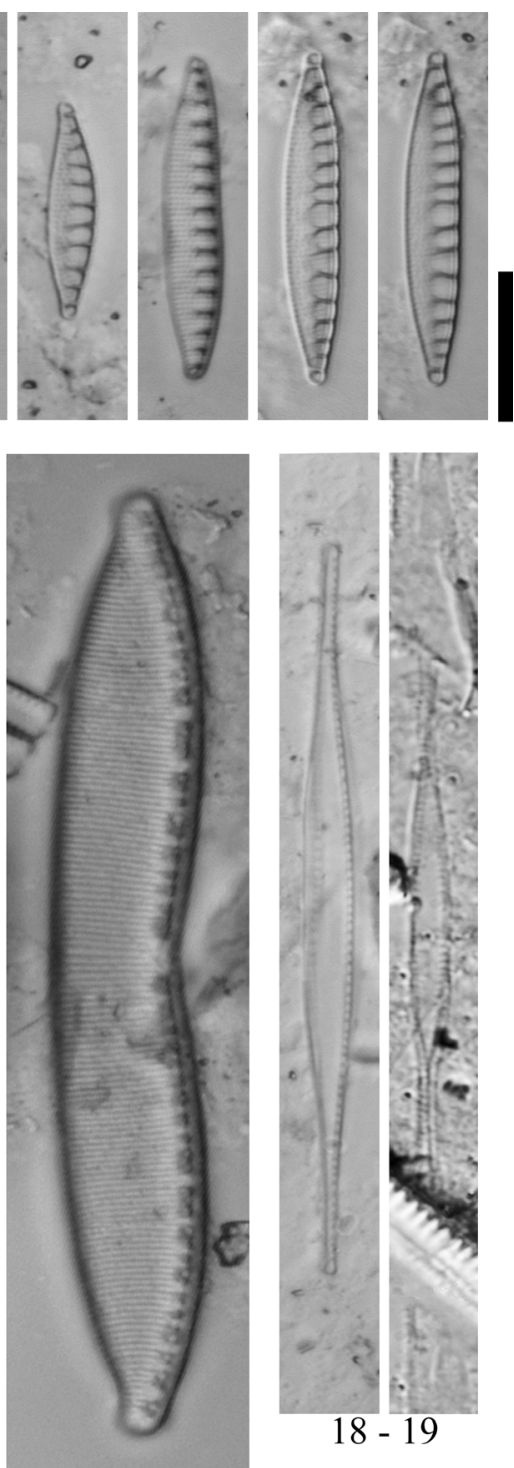

17

Figuras 1-19. Representantes de Bacillariaceae no Parque Estadual das Fontes do Ipiranga, São Paulo, SP, Brazil. 1-11. Grunowia solgensis (Cleve-Euler) Aboal; 12-16. Hantzschia amphyoxis (Ehrenberg) Grunow; 17. Hantzschia sp.; 18-19. Nitzschia acicularis (Kützing) W. Smith. Barra de escala $=10 \mu \mathrm{m}$.

Figures 1-19. Bacillariaceae representatives in the Parque Estadual das Fontes do Ipiranga, São Paulo, SP, Brazil. 1-11. Grunowia solgensis (Cleve-Euler) Aboal; 12-16. Hantzschia amphyoxis (Ehrenberg) Grunow; 17. Hantzschia sp.; 18-19. Nitzschia acicularis (Kützing) W. Smith. Scale bar $=10 \mu \mathrm{m}$. 
* Nitzschia acidoclinata Lange-Bertalot, Nova Hedwigia 28: 277, pl. 7, fig. 19-21, pl. 10, fig. 1-2. 1976.

Figuras 20-43

Frústulas simétricas nos planos lateral e apical, linearlanceoladas a lanceoladas ou elípticas, ápices pouco protraídos, estreitos; estrias de difícil visualização; aréolas inconspícuas ao microscópio óptico; canal da rafe marginal, fíbulas de distribuição regular, curtas, retangulares, as centrais mais espaçadas; medidas: eixo apical 16-44,5 $\mu \mathrm{m}$, eixo transapical 2-3 $\mu \mathrm{m}, 10-14$ fibulas em $10 \mu \mathrm{m}, 29-32$ estrias em $10 \mu \mathrm{m}$.

Material examinado: BRASIL. São Paulo: São Paulo, Parque Estadual das Fontes do Ipiranga, Jardim Botânico, córrego Pirarungáua, 18-VII-1991, D.C. Bicudo, T.A.V. Ludwig \& D.M. Figueiredo (SP255749); Lago das Garças, 18-VII-1991, D.C. Bicudo, T.A.V.Ludwig \& D.M. Figueiredo (SP255751, SP255752); 14-I-1997, D.C. Bicudo \& L.L. Morandi (SP294904); hidrofitotério, 18-VII-1991, D.C. Bicudo, T.A.V. Ludwig \& D.M. Figueiredo (SP294903); 07-VI-2011, P.D.A. Silva, G.C. Marquardt, S.W. Ribeiro \& B. Pelegrini (SP427341, SP427342, SP427343); Lago do Monjolo, 01-III-1997, D.C. Bicudo, T.A.V. Ludwig \& L.L. Morandi (SP294909); Lago das Ninfeias, 07-XI-1996, D.C.
Bicudo \& L.L. Morandi (SP294899); sedimentos, 24-IX-2014, L.F. Costa \& D.C. Bicudo (SP469576); material sobre musgos e tronco de árvore, 07-VI-2011, P.D.A. Silva, G.C. Marquardt, S.W. Ribeiro \& B. Pelegrini (SP427344); 25-XI-2014, L.F. Costa \& D.C. Bicudo (SP469318).

Nitzschia hantzschiana assemelha-se a $N$. acidoclinata na forma da valva, dos ápices e na separação entre as fíbulas centrais, bem como no comprimento das valvas e na densidade de fíbulas. No entanto, a diferença ocorre quando se comparam a largura da valva e a densidade de estrias, 3 a 5 $\mu \mathrm{m}$ e 20 a 26 em $10 \mu \mathrm{m}$, respectivamente, em $N$. hantzschiana (Hoffman et al. 2013).

Nitzschia amphibia Grunow, Verhandlungen der kaiserlich-königlichen zoologisch-botanischen Gesellschaft in Wien 1862: 574, pl. 28, fig. 23. 1862.

\section{Figuras 44-51}

Frústulas simétricas nos planos lateral e apical; valvas lanceoladas ou margens paralelas, ápices rostrados a arredondados; estrias unisseriadas, paralelas no centro, curvadas próximo dos ápices; aréolas circulares ou elípticas, facilmente discerníveis ao microscópio óptico; canal da rafe
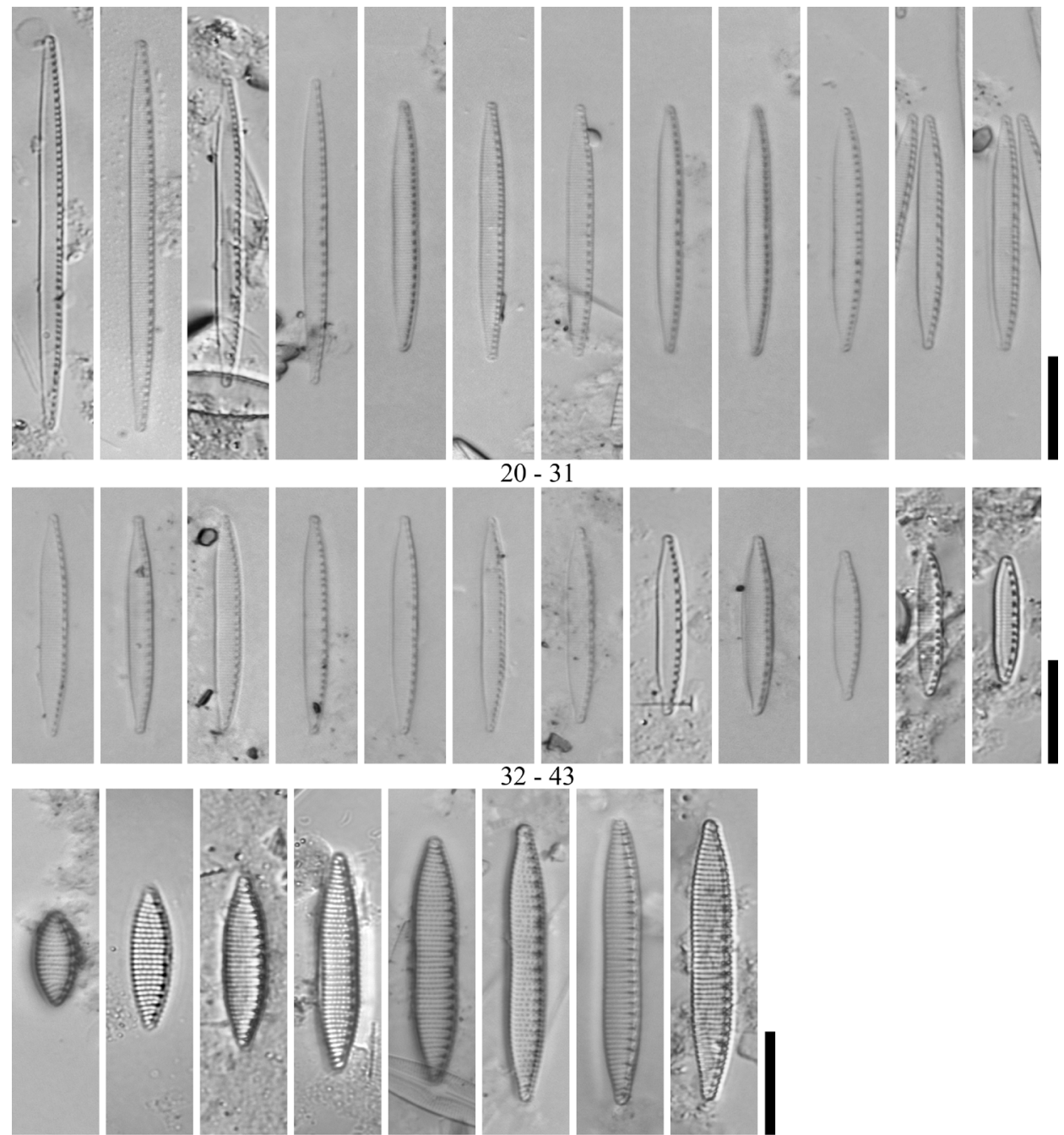

Figuras 20-51. Representantes de Bacillariaceae no Parque Estadual das Fontes do Ipiranga, São Paulo, SP, Brazil. 20-43. Nitzschia acidoclinata Lange-Bertalot; 44-51. Nitzschia amphibia Grunow. Barra de escala $=10 \mu \mathrm{m}$.

Figures 20-51. Bacillariaceae representatives in the Parque Estadual das Fontes do Ipiranga, São Paulo, SP, Brazil. 20-43. Nitzschia acidoclinata Lange-Bertalot; 44-51. Nitzschia amphibia Grunow. Scale bar $=10 \mu \mathrm{m}$. 
marginal, fibulas distribuídas regularmente, curtas, cuneadas ou retangulares, podendo se estender por 1-3 interestrias, às vezes parecendo raiz de um dente; o maior espaçamento das estrias na região central pode ser visível em alguns exemplares graças à distribuição mais ou menos irregular das fíbulas; medidas: eixo apical 11-33 $\mu \mathrm{m}$, eixo transapical 3,5-4,5 $\mu \mathrm{m}, 6-10$ fíbulas em $10 \mu \mathrm{m}, 17-19$ estrias em $10 \mu \mathrm{m}$, ca. 17 aréolas em $10 \mu \mathrm{m}$.

Material examinado: BRASIL. São Paulo: São Paulo, Parque Estadual das Fontes do Ipiranga, Jardim Botânico, Lago das Garças, 18-VII-1991, D.C. Bicudo, T.A.V. Ludwig \& D.M. Figueiredo (SP255752); Lago das Ninfeias, 07-XI1996, D.C. Bicudo \& L.L. Morandi (SP294899); hidrofitotério, 18-VII-1991, D.C. Bicudo, T.A.V.Ludwig \& D.M. Figueiredo (SP427343); material sobre musgos e tronco de árvore, 07VI-2011, P.D.A. Silva, G.C. Marquardt, S.W. Ribeiro \& B. Pelegrini (SP427344).

* Nitzschia clausii Hantzsch, Hedwigia 2(7):40,pl.4, fig. 7. 1860. Figuras 63-66

Frústulas assimétricas nos planos lateral e apical; valvas lineares, margens paralelas, às vezes concavidade na região central do contorno da valva, ápices cuneados, voltados para lados opostos, arredondados a rostrados; canal da rafe marginal, fíbulas distribuídas regularmente, mais espaçadas no centro; fíbulas curtas, algumas mais largas; estrias finas, de difícil vizualisação, paralelas; aréolas muito delicadas, sigmoides em vista pleural; possível visualizar as fíbulas e sua distribuição, bem como a simetria hantzschioide; medidas: eixo apical 30-67 $\mu \mathrm{m}$, eixo transapical 2,5-4,5 $\mu \mathrm{m}$, eixo pervalvar ca. $6 \mu \mathrm{m}, 6-12$ fibulas em $10 \mu \mathrm{m}$, ca. 34 estrias em $10 \mu \mathrm{m}$.

Material examinado: BRASIL. São Paulo: São Paulo, Parque Estadual das Fontes do Ipiranga, Jardim Botânico, córrego Pirarungáua, 18-VII-1991, D.C. Bicudo, T.A.V. Ludwig \& D.M. Figueiredo (SP255749); Lago das Garças, 18-VII-1991, D.C. Bicudo, T.A.V. Ludwig \& D.M. Figueiredo (SP255751); hidrofitotério, 18-VII-1991, D.C. Bicudo, T.A.V. Ludwig \& D.M. Figueiredo (SP294903); 07-VI-2011, P.D.A. Silva, G.C. Marquardt, S.W. Ribeiro \& B. Pelegrini (SP427341).

* Nitzschia dissipata (Kützing) Rabenhorst, DieAlgen Sachsens. 968. 1860 三 Synedra dissipata Kützing, Die Kieselschaligen Bacillarien oder Diatomeen. 64, pl. 14, fig. 3. 1844.

Figuras 67, 68

Frústulas simétricas no plano apical; valvas lanceoladas, ápices cuneados a rostrados; estrias e aréolas inconspícuas ao microscópio óptico; canal da rafe marginal ou submarginal, fíbulas mais ou menos regularmente distribuídas, sem distinção das centrais, formato retangular, curtas, estreitas;
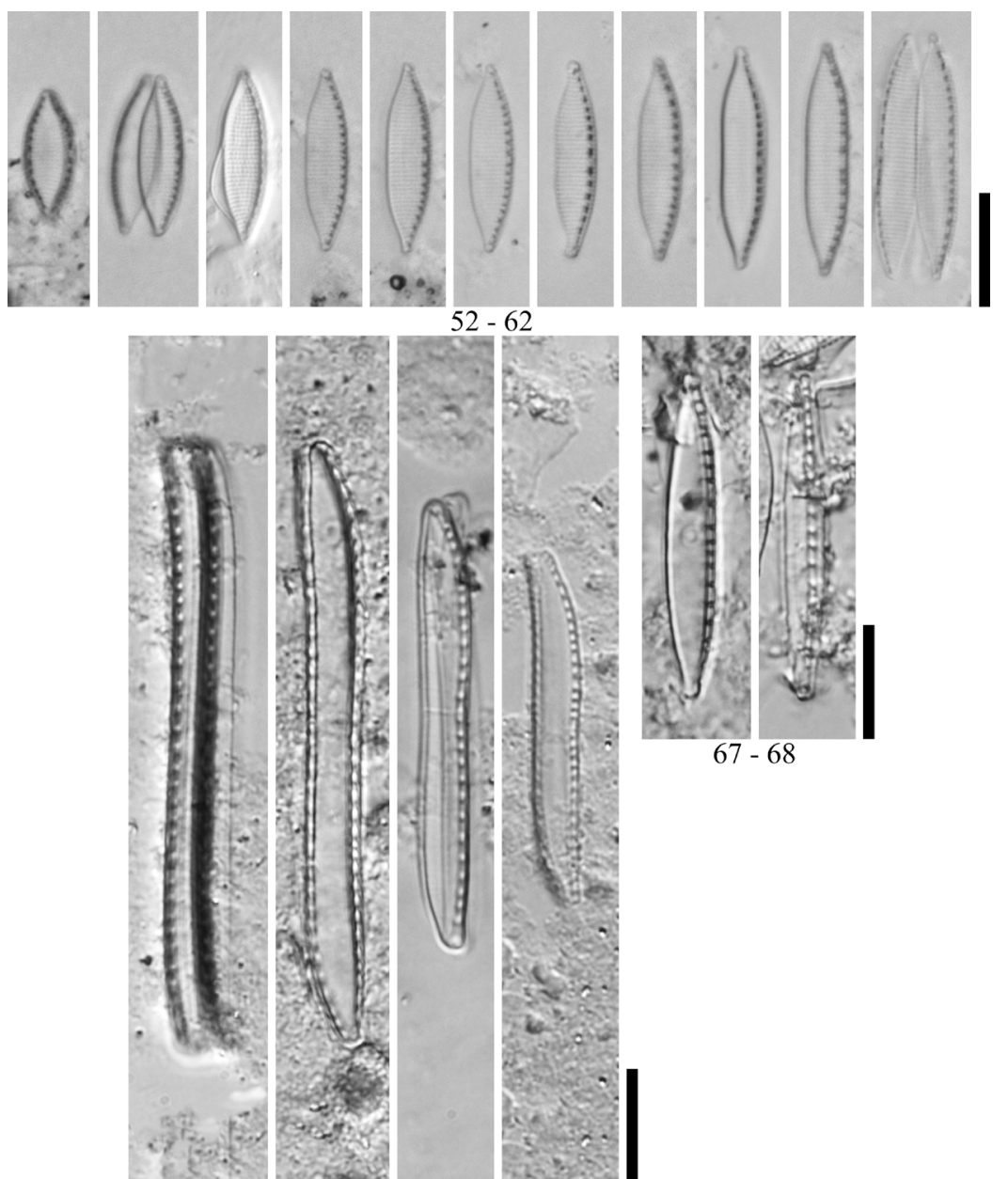

$67-68$

$63-66$

Figuras 52-68. Representantes de Bacillariaceae no Parque Estadual das Fontes do Ipiranga, São Paulo, SP, Brazil. 52-62. Nitzschia frustulum (Kützing) Grunow; 63-66. Nitzschia clausii Hantzsch; 67-68. Nitzschia dissipata (Kützing) Rabenhorst. Barra de escala $=10 \mu \mathrm{m}$.

Figures 52-68. Bacillariaceae representatives in the Parque Estadual das Fontes do Ipiranga, São Paulo, SP, Brazil. 52-62. Nitzschia frustulum (Kützing) Grunow; 63-66. Nitzschia clausii Hantzsch; 67-68. Nitzschia dissipata (Kützing) Rabenhorst. Scale bar $=10 \mu \mathrm{m}$. 
medidas: eixo apical $23-29 \mu \mathrm{m}$, eixo transapical 3,5-4,5 $\mu \mathrm{m}$, 7-8 fíbulas em $10 \mu \mathrm{m}$.

Material examinado: BRASIL. São Paulo: São Paulo, Parque Estadual das Fontes do Ipiranga, Jardim Botânico, Lago das Ninfeias, 07-XI-1996, D.C. Bicudo \& L.L. Morandi (SP294900); hidrofitotério, 07-XI-1996, D.C. Bicudo \& L.L. Morandi (294903).

** Nitzschia dissipata (Kützing) Rabenhorst var. borneensis Kützing in Schmidt, Atlas der Diatomaceen-Kunde. pl. 335, fig. 22-24. 1921.

Figuras 69-74

Frústulas simétricas nos planos lateral e apical; valvas lineares, margens paralelas, terminações cuneadas, levemente assimétricas, ápices rostrados, proeminentes; estrias e aréolas inconspícuas ao microscópio óptico; canal da rafe excêntrico, fíbulas distribuídas irregularmente, sem distinção das centrais, formato retangular, curtas, estreitas; nódulo central ausente; medidas: eixo apical 43-47 $\mu \mathrm{m}$, eixo transapical 5-6 $\mu \mathrm{m}, 5-9$ fíbulas em $10 \mu \mathrm{m}$.
Material examinado: BRASIL. São Paulo: São Paulo, Parque Estadual das Fontes do Ipiranga, Jardim Botânico, hidrofitotério, 07-VI-2011, P.D.A. Silva, G.C. Marquardt, S.W. Ribeiro \& B. Pelegrini (SP427341).

Nitzschia elegantula van Heurk, Synopsis des Diatomées de Belgique, Atlas. pl. 69, fig. 22a. 1880.

Figuras 75-85

Frústulas pequenas, simétricas nos planos apical e lateral; valvas lineares, ápices capitados; canal da rafe marginal, fíbulas distribuídas regularmente, sem distinção das centrais, formato quadrado ou retangular, curtas; estrias finas; aréolas inconspícuas; medidas: eixo apical 12,5-22 $\mu \mathrm{m}$, eixo transapical 3-3,5 $\mu \mathrm{m}, 7-13$ fíbulas em $10 \mu \mathrm{m}$, 24-26 estrias em $10 \mu \mathrm{m}$.

Material examinado: BRASIL. São Paulo: São Paulo, Parque Estadual das Fontes do Ipiranga, Jardim Botânico, hidrofitotério, 07-XI-1996, D.C. Bicudo \& L.L. Morandi (SP294903); 07-VI-2011, P.D.A. Silva, G.C. Marquardt, S.W. Ribeiro \& B. Pelegrini (SP427343); hidrofitotério,
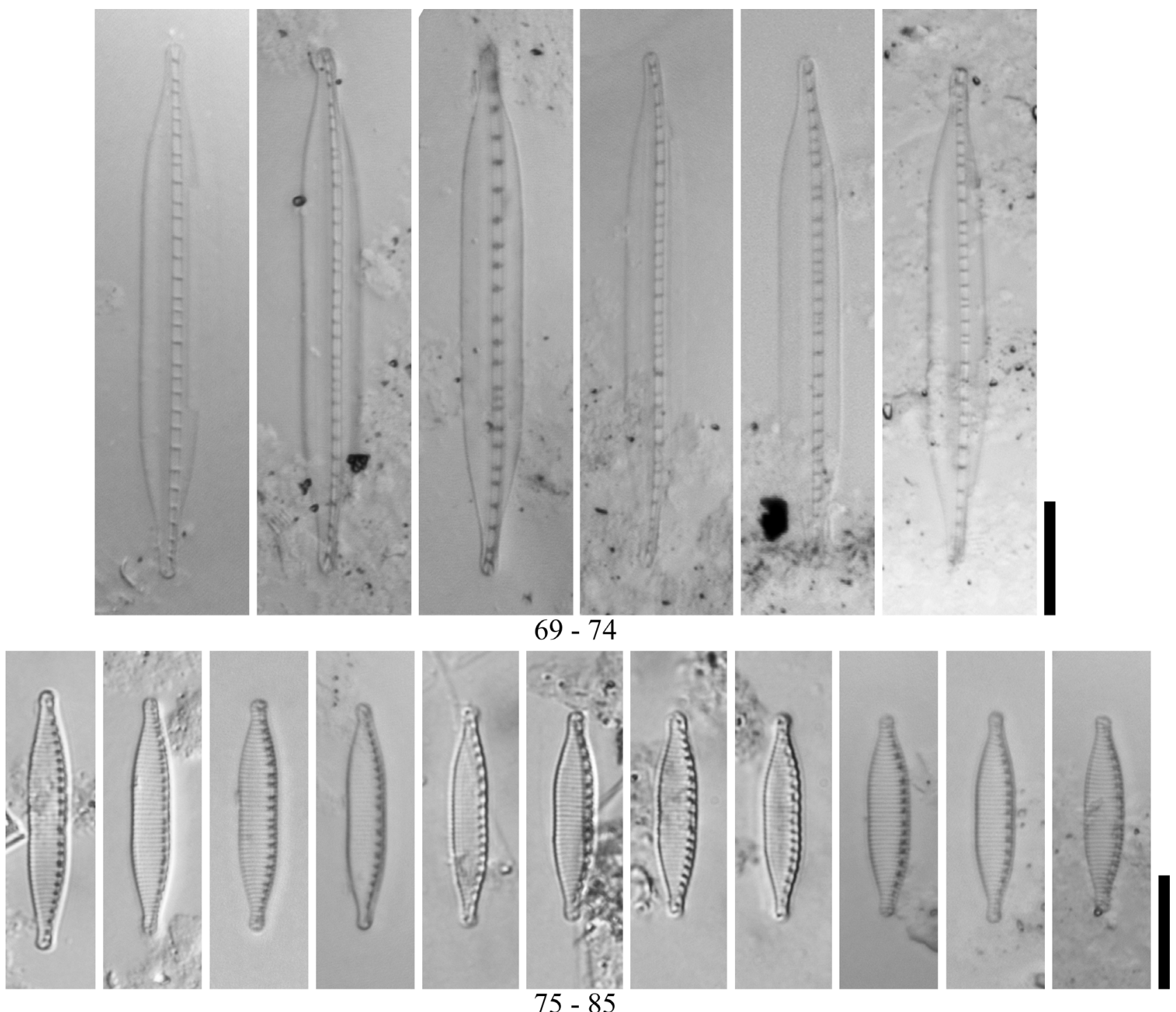

Figuras 69-85. Representantes de Bacillariaceae no Parque Estadual das Fontes do Ipiranga, São Paulo, SP, Brazil. 69-74. Nitzschia dissipata (Kützing) Rabenhorst var. borneensis Kützing; 75-85. Nitzschia elegantula van Heurk. Barra de escala $=10 \mu \mathrm{m}$.

Figures 69-85. Bacillariaceae representatives in the Parque Estadual das Fontes do Ipiranga, São Paulo, SP, Brazil. 69-74. Nitzschia dissipata (Kützing) Rabenhorst var. borneensis Kützing; 75-85. Nitzschia elegantula van Heurk. Scale bar $=10 \mu \mathrm{m}$. 
12-IV-2017, S.A. Oliveira, K.S. Morais \& C.E.M. Bicudo (SP469783); Lago das Ninfeias, sedimentos, 24-IX-2014, L.F. Costa \& D.C. Bicudo (SP469576); material sobre musgos e tronco de árvore, 07-VI-2011, P.D.A. Silva, G.C. Marquardt, S.W. Ribeiro \& B. Pelegrini (SP427344).

Nitzschia frustulum (Kützing) Grunow in Cleve \& Grunow, Kongliga Svenska Vetenskaps-Akademiens Handlingar 17(2): 98, pl. 68, fig. 1-2. 1880 三 Synedra frustulum Kützing, Die Kieselschaligen Bacillarien oder Diatomeen. 63, pl. 30, fig. 77. 1844.

Figuras 52-62

Frústulas simétricas nos planos apical e lateral; valvas linear-lanceoladas, ápices rostrados a subcapitados; estrias unisseriadas, paralelas no centro, curvadas próximo dos ápices; aréolas às vezes visíveis dependendo do foco do microscópio óptico; canal da rafe marginal, fíbulas regularmente distribuídas, curtas, quadradas ou retangulares; fíbulas centrais mais espaçadas que as demais; medidas: eixo apical 14-20 $\mu \mathrm{m}$, eixo transapical 3,5-4 $\mu \mathrm{m}, 9-13$ fíbulas em $10 \mu \mathrm{m}, 26-27$ estrias em $10 \mu \mathrm{m}$.

Material examinado: BRASIL. São Paulo: São Paulo, Parque Estadual das Fontes do Ipiranga, Jardim Botânico, hidrofitotério, 18-VII-1991, D.C. Bicudo, T.A.V. Ludwig \& D.M. Figueiredo (SP427342); material sobre musgos e tronco de árvore, 07-VI-2011, P.D.A. Silva, G.C. Marquardt, S.W. Ribeiro \& B. Pelegrini (SP427344).

Os espécimes examinados durante este estudo apresentaram ápices levemente mais estreitos e cuneados que os registrados por Trobajo et al. (2013). Entretanto, as características morfológicas e métricas como forma da valva, formato das fíbulas, presença de espaçamento das fíbulas centrais, eixo apical, eixo transapical e densidade de estrias e fíbulas condizem com as medições previamente realizadas do tipo nomenclatural.

Nitzschia gracilis Hantzsch, Hedwigia 2(7): 40, pl. 6, fig. 8. 1860 .

Figuras 86-91

Frústulas simétricas nos planos lateral e apical, simetria nitzschioide; valvas longas, extremidades cônicas, ápices arredondados, margens paralelas; canal da rafe marginal, fíbulas curtas, distribuição regular, sem espaçamento na região central; estrias de difícil visualização e aréolas inconspícuas; medidas: eixo apical 39-60 $\mu \mathrm{m}$, eixo transapical 2,5-3 $\mu \mathrm{m}, 12-18$ fíbulas em $10 \mu \mathrm{m}$.

Material examinado: BRASIL. São Paulo: São Paulo, Parque Estadual das Fontes do Ipiranga, Jardim Botânico, Lago das Garças, 18-VII-1991, D.C. Bicudo, T.A.V. Ludwig \& D.M. Figueiredo (SP255751); 14-I-1997, D.C. Bicudo \& L.L. Morandi (SP294905); hidrofitotério, 12-IV-2017, S.A. Oliveira, K.S. Morais \& C.E.M. Bicudo (SP469783).

Nitzschia gracilis Hantzsch pode ser confundida com $N$. acicularis (Kützing) W. Smith em certos aspectos morfológicos como aréolas inconspícuas, formato e distribuição das fíbulas, sem maior separação das fíbulas centrais e as medidas dos eixos apical e transapical e a densidade de fíbulas podem mostrar sobreposições. No entanto, para a diferenciação é possível ver o formato da valva linear com extremidades cônicas em $N$. gracilis, porém, muito protraídas em $N$. acicularis. As estrias de dífícil visualiação em $N$. gracilis podem ser vistas com a mudança de foco no microscópio óptico, no entanto, não é possível observar o mesmo em $N$. acicularis, pois são inconspícuas. Nitzschia subacicularis Hustedt assemelha-se a $N$. gracilis quanto às medidas do comprimento e da largura da frústula e à densidade de fíbulas no espaço linear de 10 $\mu \mathrm{m}$. No entanto, características como formato alongado da valva, margens paralelas e ápices valvares arredondados em $N$. gracilis Hantzsch e forma lanceolada da valva com ápices afilados em $N$. subacicularis Hustedt diferenciam suficientemente as duas espécies.

Nitzschia inconspicua Grunow, Verhandlungen der KaiserlichKöniglichen Zoologisch-Botanischen Gesellschaft in Wien 12: 579, pl. 28, fig. 25. 1862.

Figuras 92-107

Frústulas simétricas nos planos lateral e apical; valvas linear-lanceoladas a lanceoladas nos espécimes maiores, elíptico-lanceoladas nos espécimes menores, ápices estreitos, sutilmente prolongados, rostrados a arredondados, tendendo a arredondados nos exemplares menores; estrias paralelas no centro da valva, divergentes próximo dos ápices; aréolas de difícil visualização ao microscópio óptico; canal da rafe marginal, fíbulas de distribuição regular, curtas, retangulares, fíbulas centrais mais espaçadas; medidas: eixo apical 9-21 $\mu \mathrm{m}$, eixo transapical 2-3,5 $\mu \mathrm{m}$, eixo pervalvar 2-3 $\mu \mathrm{m}, 8-16$ fíbulas em $10 \mu \mathrm{m}, 21-30$ estrias em $10 \mu \mathrm{m}, 21-35$ aréolas em $10 \mu \mathrm{m}$.

Material examinado: BRASIL. São Paulo: São Paulo, Parque Estadual das Fontes do Ipiranga, Jardim Botânico, Lago das Garças, 18-VII-1991, D.C. Bicudo, T.A.V. Ludwig \& D.M. Figueiredo (SP255752); Lago das Ninfeias, 07-XI-1996, D.C. Bicudo \& L.L. Morandi (SP294899); 25-XI-2014, L.F. Costa \& D.C. Bicudo (SP469318); hidrofitotério, 18-VII-1991, D.C. Bicudo, T.A.V. Ludwig \& D.M. Figueiredo (SP427343); 12-IV-2017, S.A. Oliveira, K.S. Morais \& C.E.M. Bicudo (SP469783); material sobre musgos e tronco de árvore, 07-VI-2011, P.D.A. Silva, G.C. Marquardt, S.W. Ribeiro \& B. Pelegrini (SP427344).

Apesar da semelhança morfológica e métrica entre $N$. inconspicua e $N$. soratensis, pode-se diferi-las com base nos ápices mais agudos e nas fíbulas menores e retangulares em N. inconspicua (Cantonati et al. 2017).

* Nitzschia intermedia Hantzsch in Cleve \& Grunow, Beiträge zur Kenntniss der Arctischen Diatomeen 17(2): 95. 1880

Figuras 108-114

Frústulas simétricas nos planos lateral e apical, margens lineares, paralelas; valvas robustas; ápices cuneados; estrias paralelas no centro, divergentes próximo dos ápices, às vezes de difícil visualização ao microscópio óptico; aréolas igualmente de difícil visualização ao microscópio 

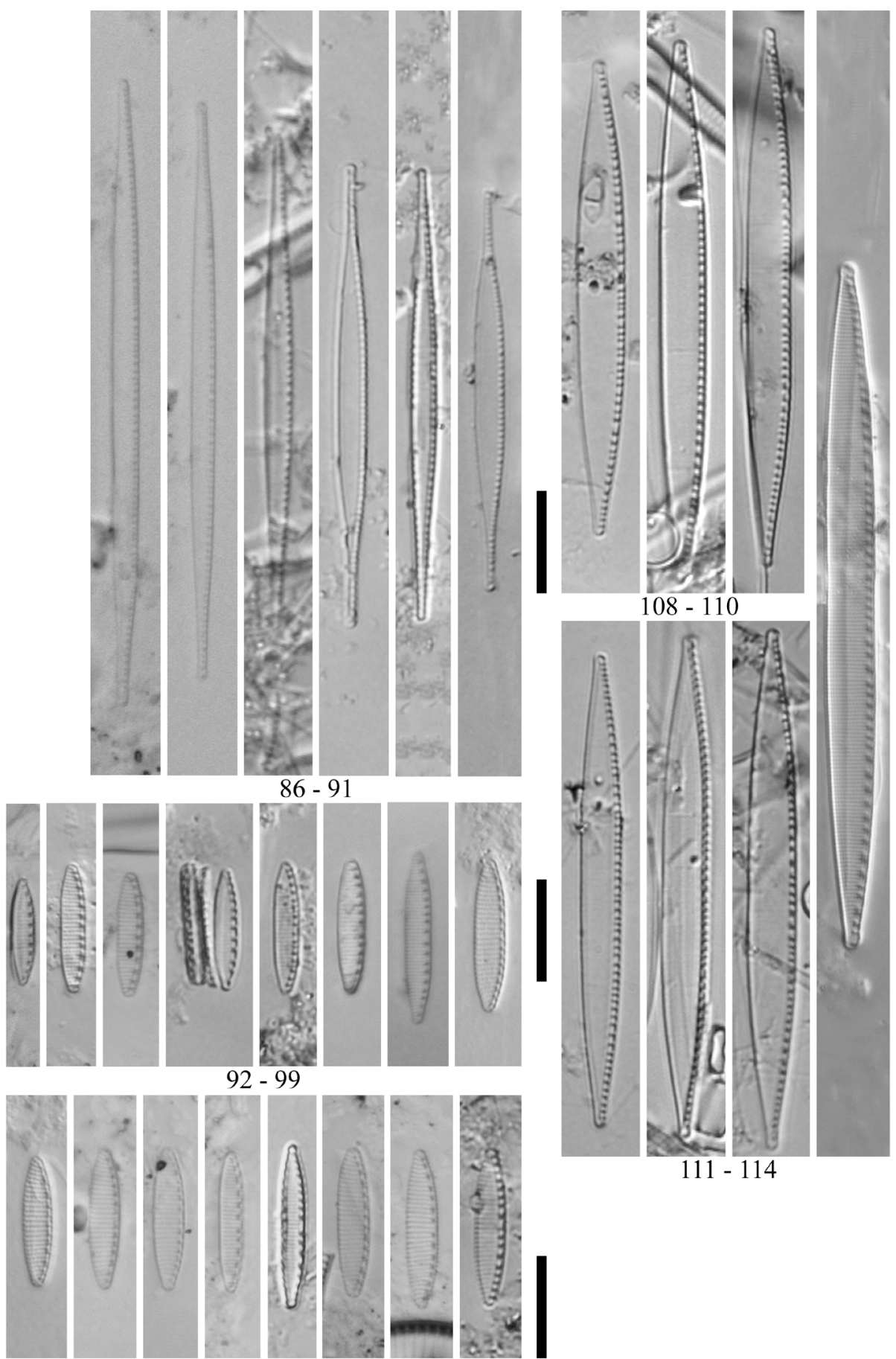

$111-114$

$100-107$

Figuras 86-114. Representantes de Bacillariaceae no Parque Estadual das Fontes do Ipiranga, São Paulo, SP, Brazil. 86-91. Nitzschia gracilis Hantzsch; 92-107. Nitzschia inconspicua Grunow; 108-114. Nitzschia intermedia Hantzsch. Barra de escala $=10 \mu \mathrm{m}$.

Figures 86-114. Bacillariaceae representatives in the Parque Estadual das Fontes do Ipiranga, São Paulo, SP, Brazil. 86-91. Nitzschia gracilis Hantzsch; 92-107. Nitzschia inconspicua Grunow; 108-114. Nitzschia intermedia Hantzsch. Scale bar $=10 \mu \mathrm{m}$.

óptico; canal da rafe marginal, fíbulas curtas, distribuídas irregularmente, sem espaçamento maior das centrais; medidas: eixo apical 67-105 $\mu \mathrm{m}$, eixo transapical 4,5-5 $\mu \mathrm{m}$, 8-9 fibulas em $10 \mu \mathrm{m}, 27-28$ estrias em $10 \mu \mathrm{m}, 18-26$ aréolas em $10 \mu \mathrm{m}$.

Material examinado: BRASIL. São Paulo: São Paulo, Parque Estadual das Fontes do Ipiranga, Jardim Botânico, Lago das Garças, 14-I-1997, D.C. Bicudo \& L.L. Morandi (SP294904, SP294905); hidrofitotério, 18-VII-1991, D.C.
Bicudo, T.A.V.Ludwig \& D.M. Figueiredo (SP427342); 12-IV2017, S.A. Oliveira, K.S. Morais \& C.E.M. Bicudo (SP469783).

Nitzschia linearis W. Smith, Synopsis of British Diatomaceae 1: 39, pl. 13, fig. 110, pl. 31, fig. 110. 1853 .

Figuras 115-119

Frústulas assimétricas no plano lateral, margem lateral (sem rafe) linear, margem lateral (com rafe) biconvexa ou concavidade tênue na região central, ápices cuneados, assimétricos, margem lateral com rafe mais ou menos 
convexa, margem lateral sem rafe mais ou menos côncava; estrias paralelas por toda valva, formadas por aréolas nem sempre visíveis ao microscópio óptico; canal da rafe marginal, fíbulas de distribuição mais ou menos regular, centrais mais espaçadas que as demais; fíbulas retangulares ou em forma de cone; medidas: eixo apical 67-141 $\mu \mathrm{m}$, eixo transapical 4-6 $\mu \mathrm{m}$, eixo pervalvar ca. $7 \mu \mathrm{m}, 10-13$ fíbulas em $10 \mu \mathrm{m}, 32-36$ estrias em $10 \mu \mathrm{m}, 25-40$ aréolas em $10 \mu \mathrm{m}$.

Material examinado: BRASIL. São Paulo: São Paulo, Parque Estadual das Fontes do Ipiranga, Jardim Botânico, hidrofitotério, 07-VI-2011, P.D.A. Silva, G.C. Marquardt, S.W. Ribeiro \& B. Pelegrini (SP427341, SP427342, SP427343); 18-VII-1991, D.C. Bicudo, T.A.V. Ludwig \& D.M. Figueiredo (SP255745); 12-IV-2017, S.A.
Oliveira, K.S. Morais \& C.E.M. Bicudo (SP469783); Lago dos Bugios 07-XI-1996, D.C. Bicudo \& L.L. Morandi (SP294901); material sobre musgos e tronco de árvore, 07-VI-2011, P.D.A. Silva, G.C. Marquardt, S.W. Ribeiro \& B. Pelegrini (SP427344).

Nitzschia palea (Kützing) W. Smith var. palea, Synopsis of British Diatomaceae 2: 89. 1856 三 Synedra palea Kützing, Die Kieselschaligen Bacillarien oder Diatomeen. 63, pl. 3, fig. 27. 1844.

Figuras 120-137

Frústulas simétricas nos planos lateral e apical; valvas lanceoladas, ápices cuneados ou rostrados; estrias muitas vezes de difícil visualização, aréolas inconspícuas ao microscópio óptico; canal da rafe marginal, fíbulas curtas,

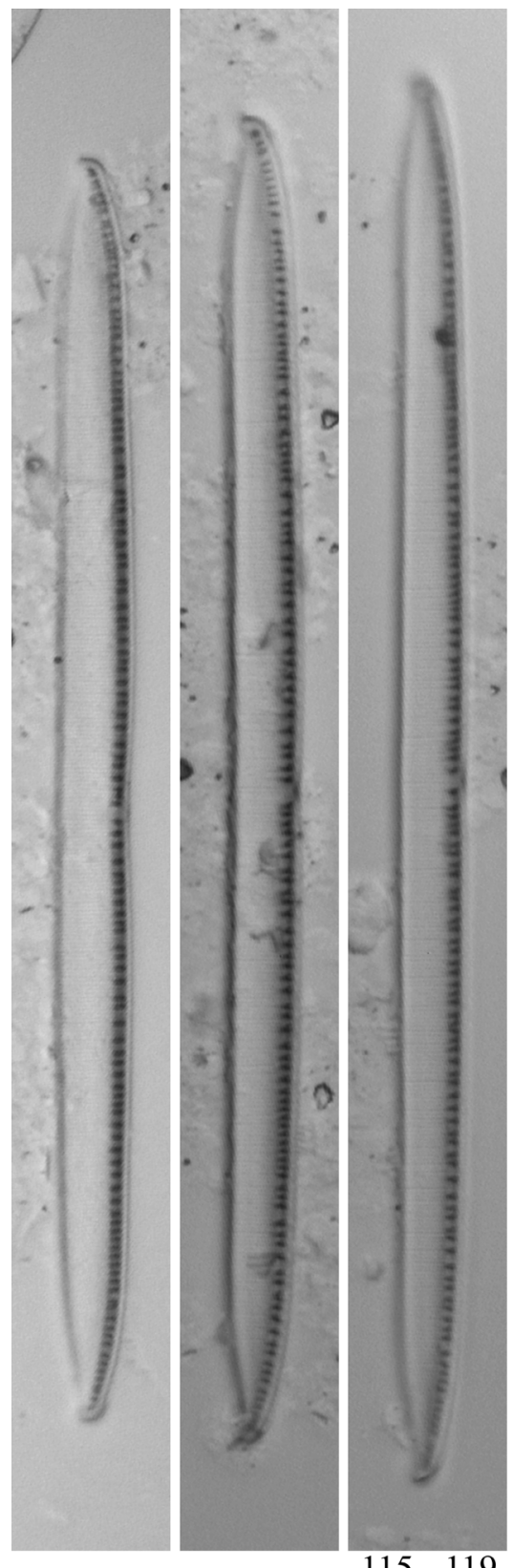

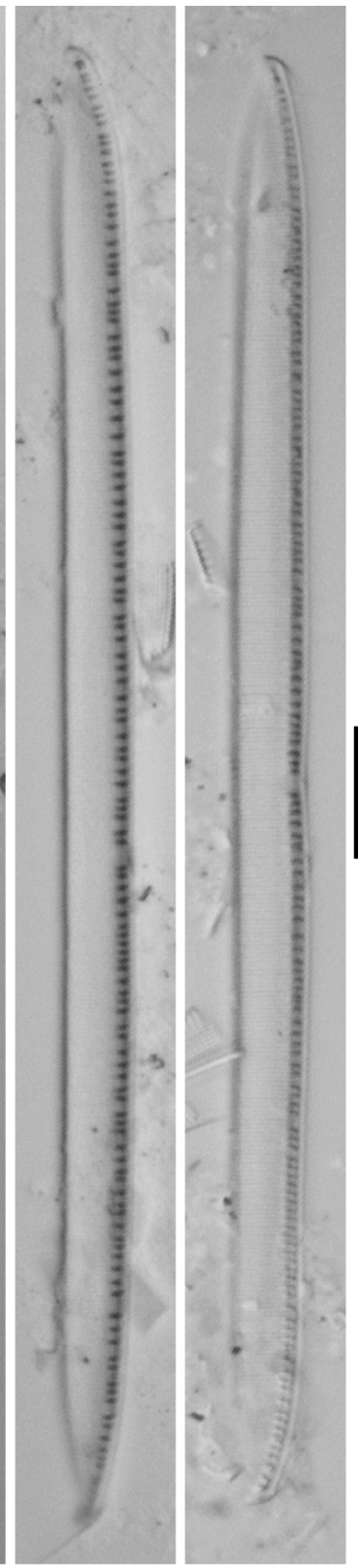

$115-119$
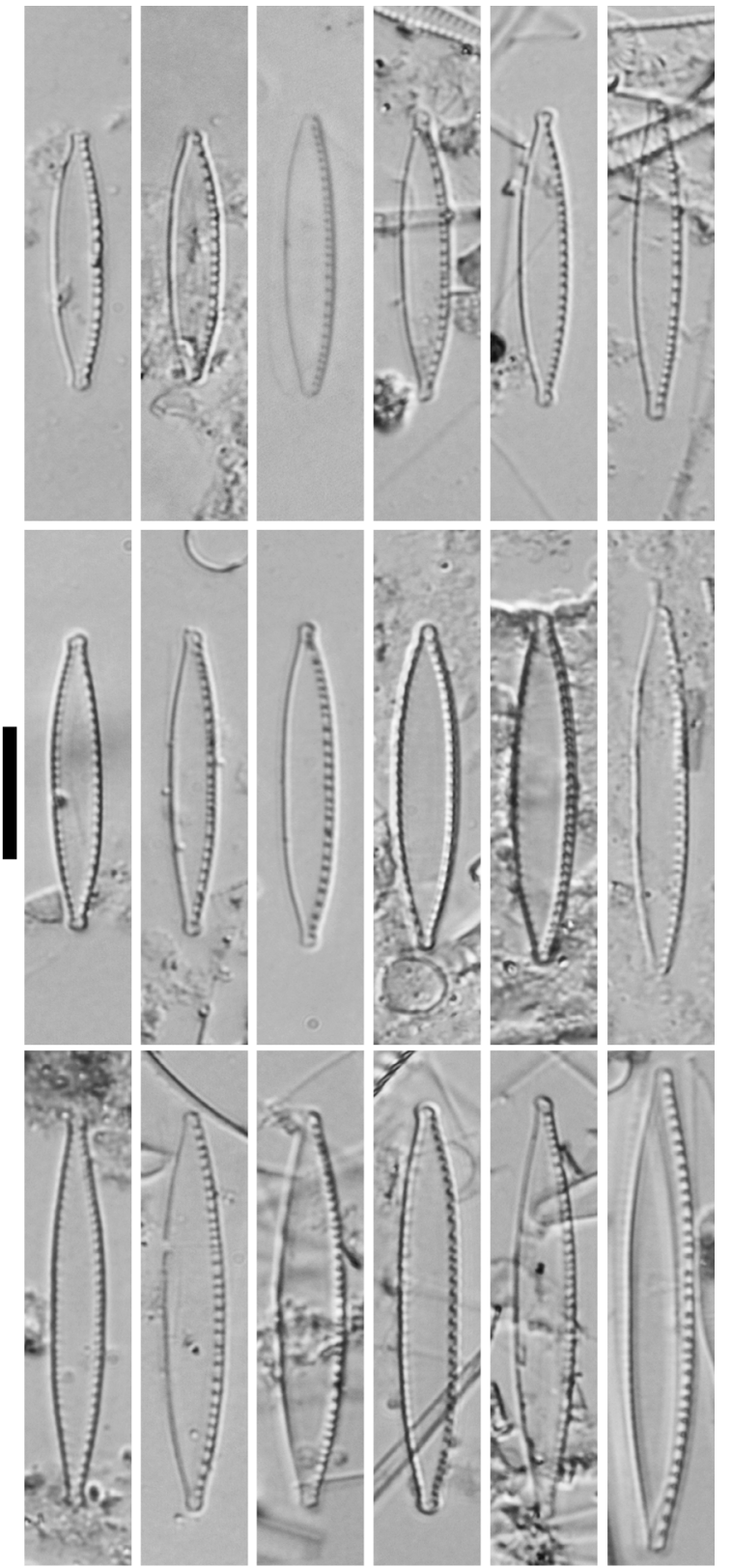

$120-137$

Figuras 115-137. Representantes de Bacillariaceae no Parque Estadual das Fontes do Ipiranga, São Paulo, SP, Brazil. 115-119. Nitzschia linearis W. Smith; 120-137. Nitzschia palea (Kützing) W. Smith var. palea. Barra de escala $=10 \mu \mathrm{m}$.

Figures 115-137. Bacillariaceae representatives in the Parque Estadual das Fontes do Ipiranga, São Paulo, SP, Brazil. 115-119. Nitzschia linearis W. Smith; 120-137. Nitzschia palea (Kützing) W. Smith var. palea. Scale bar $=10 \mu \mathrm{m}$. 
distribuídas regularmente, contínuas, sem interrupção no centro do canal da rafe; medidas: eixo apical 17-52 $\mu \mathrm{m}$, eixo transapical 3-5 $\mu \mathrm{m}, 8-17$ fíbulas em $10 \mu \mathrm{m}, 32-37$ estrias em $10 \mu \mathrm{m}$.

Material examinado: BRASIL. São Paulo: São Paulo, Parque Estadual das Fontes do Ipiranga, Jardim Botânico, Lago das Garças, 18-VII-1991, D.C. Bicudo, T.A.V. Ludwig \& D.M. Figueiredo (SP255751); 14-I-1997, D.C. Bicudo \& L.L. Morandi (SP294904, SP294905); Lago dos Bugios, 07-XI-1996, D.C. Bicudo \& L.L. Morandi (SP294901); hidrofitotério, 15-I-1997, D.C. Bicudo \& L.L. Morandi (SP294903); 07-VI-2011, P.D.A. Silva, G.C. Marquardt, S.W. Ribeiro \& B. Pelegrini (SP427341, SP427342); 12IV-2017, S.A. Oliveira, K.S. Morais \& C.E.M. Bicudo (SP469783); Lago do IAG, 15-I-1997, D.C. Bicudo \& L.L. Morandi (SP294907); Lago das Ninfeias 24-IX-2014, L.F. Costa \& D.C. Bicudo (SP469315, SP469316, SP469317, SP469318); material sobre musgos e tronco de árvore, 07VI-2011, P.D.A. Silva, G.C. Marquardt, S.W. Ribeiro \& B. Pelegrini (SP427344).

Nitzschia palea (Kützing) W. Smith var. debilis (Kützing) Grunow in Cleve \& Grunow, Beiträge zur Kenntniss der Arctischen Diatomeen 17(2): 96. 1880 三 Synedra debilis Kützing, Die Kieselschaligen Bacillarien oder Diatomeen. 65, pl. 3, fig. 45. 1844.

Figuras 138-158

Frústulas simétricas nos planos lateral e apical; valvas lanceoladas, ápices cuneados ou rostrados; estrias muitas vezes de difícil visualização e aréolas inconspícuas ao microscópio óptico; canal da rafe marginal, fíbulas curtas, distribuição mais ou menos regular, contínuas, sem interrupção no centro do canal da rafe; medidas: eixo apical 12-34 $\mu \mathrm{m}$, eixo transapical 2,5-3 $\mu \mathrm{m}, 12-18$ fíbulas em $10 \mu \mathrm{m}$.

Material examinado: BRASIL. São Paulo: São Paulo, Parque Estadual das Fontes do Ipiranga, Jardim Botânico, córrego Pirarungáua, 18-VII-1991, D.C. Bicudo, T.A.V. Ludwig \& D.M. Figueiredo (SP255749); Lago das Garças, 18-VII-1991, D.C. Bicudo, T.A.V. Ludwig \& D.M. Figueiredo (SP255751); 14-I-1997, D.C. Bicudo \& L.L. Morandi (SP294904, SP294905); Lago das Ninfeias, 07-XI1996, D.C. Bicudo \& L.L. Morandi (SP294899, SP294900); 24-IX-2014, L.F. Costa \& D.C. Bicudo (SP469315); Lago dos Bugios, 07-XI-1996, D.C. Bicudo \& L.L. Morandi (SP294901, SP294902); hidrofitotério, 07-XI-1996, D.C. Bicudo \& L.L. Morandi (SP294903); Lago do IAG, 15I-1997, D.C. Bicudo \& L.L. Morandi (SP294906); brejo do lago do IAG, 15-I-1997, D.C. Bicudo \& L.L. Morandi (SP294908); 12-IV-2017, S.A. Oliveira, K.S. Morais \& C.E.M. Bicudo (SP469783).

Esta variedade diferiu da típica da espécie neste trabalho pela menor largura das valvas, mesmo que ainda ocorressem algumas dentro dos limites da variedade-tipo. As margens laterais são, em geral, paralelas e as medidas da densidade de fíbulas tendem a ser próximas do limite máximo obtido para $N$. palea var. palea. Os ápices valvares são cuneados e mais curtos do que nas demais variedades da espécie (Cantonati et al. 2017). Para a diferenciação apontada acima, sempre que for possível obter é necessário observar se a população tem tendência a medidas mais estreitas da largura das valvas e mais densas em fíbulas e estrias.

* Nitzschia palea (Kützing) W. Smith var. tenuirostris Grunow in van Heurck, Synopsis des Diatomées de Belgique, Atlas. pl. 69, fig. 13. 1881.

Figuras 159-165

Frústulas simétricas nos planos lateral e apical; valvas lanceoladas, terminações prolongadas; ápices cuneados ou rostrados; estrias muitas vezes de difícil visualização e aréolas inconspícuas ao microscópio óptico; canal da rafe marginal, fíbulas curtas, regularmente distribuídas, contínuas, sem interrupção no centro do canal da rafe; medidas: eixo apical 33,5-43 $\mu \mathrm{m}$, eixo transapical 3-3,5 $\mu \mathrm{m}, 11-16$ fibulas em $10 \mu \mathrm{m}$.

Material examinado: BRASIL. São Paulo: São Paulo, Parque Estadual das Fontes do Ipiranga, Jardim Botânico, Lago das Ninfeias, 07-XI-1996, D.C. Bicudo \& L.L. Morandi (SP294899); 24-IX-2014, L.F. Costa \& D.C. Bicudo (SP469315, SP469316); Lago do IAG, 15-I-1997, D.C. Bicudo \& L.L. Morandi (SP294906); hidrofitotério, 07-VI-2011, P.D.A. Silva, G.C. Marquardt, S.W. Ribeiro \& B. Pelegrini (SP427342).

A presente variedade difere da típica da espécie, basicamente, por suas valvas possuirem ápices alongados, mas também pela largura valvar, cujas medidas variam entre as mínimas e as médias da variedade-tipo da espécie. A identificação desta variedade foi feita, principalmente, pelas terminações mais prolongadas das valvas do que nas demais variedades da espécie (Cantonati et al. 2017).

Nitzschia recta Hantzsch ex Rabenhorst, Die Algen Europas. Exsic. $n^{\circ} 1283.1862$.

Figuras 166-177

Frústulas simétricas nos planos lateral e apical; valvas lanceoladas a linear-lanceoladas nos exemplares maiores, ápices assimétricos, cuneados a subcapitados; estrias e aréolas inconspícuas ao microscópio óptico; canal da rafe marginal, grosseiro, fíbulas cuneadas, distribuídas irregularmente, sem maior espaçamento das centrais; medidas: eixo apical 10,5-43 $\mu \mathrm{m}$, eixo transapical 3-4 $\mu \mathrm{m}, 6-11$ fíbulas em $10 \mu \mathrm{m}$.

Material examinado: BRASIL. São Paulo: São Paulo, Parque Estadual das Fontes do Ipiranga, Jardim Botânico, Lago dos Bugios, 18-VII-1991, D.C. Bicudo, T.A.V.Ludwig \& D.M. Figueiredo (SP255747); Lago das Ninfeias, 07-XI-1996, D.C. Bicudo \& L.L. Morandi (SP294900); hidrofitotério, 18VII-1991, D.C. Bicudo, T.A.V. Ludwig \& D.M. Figueiredo (SP294903); 07-VI-2011, P.D.A. Silva, G.C. Marquardt, S.W. Ribeiro \& B. Pelegrini (SP427341, SP427342, SP427343); Lago do IAG, 15-I-1997, D.C. Bicudo \& L.L. Morandi (SP294907); material sobre musgos e tronco de árvore, 07VI-2011, P.D.A. Silva, G.C. Marquardt, S.W. Ribeiro \& B. Pelegrini (SP427344).

Nitzschia semirobusta Lange-Bertalot, Bibliotheca Diatomologica 27: 149, pl. 120, fig. 3-21, pl. 122, fig. 7, pl. 123, fig. 1-7. 1993. Figuras 178-188 

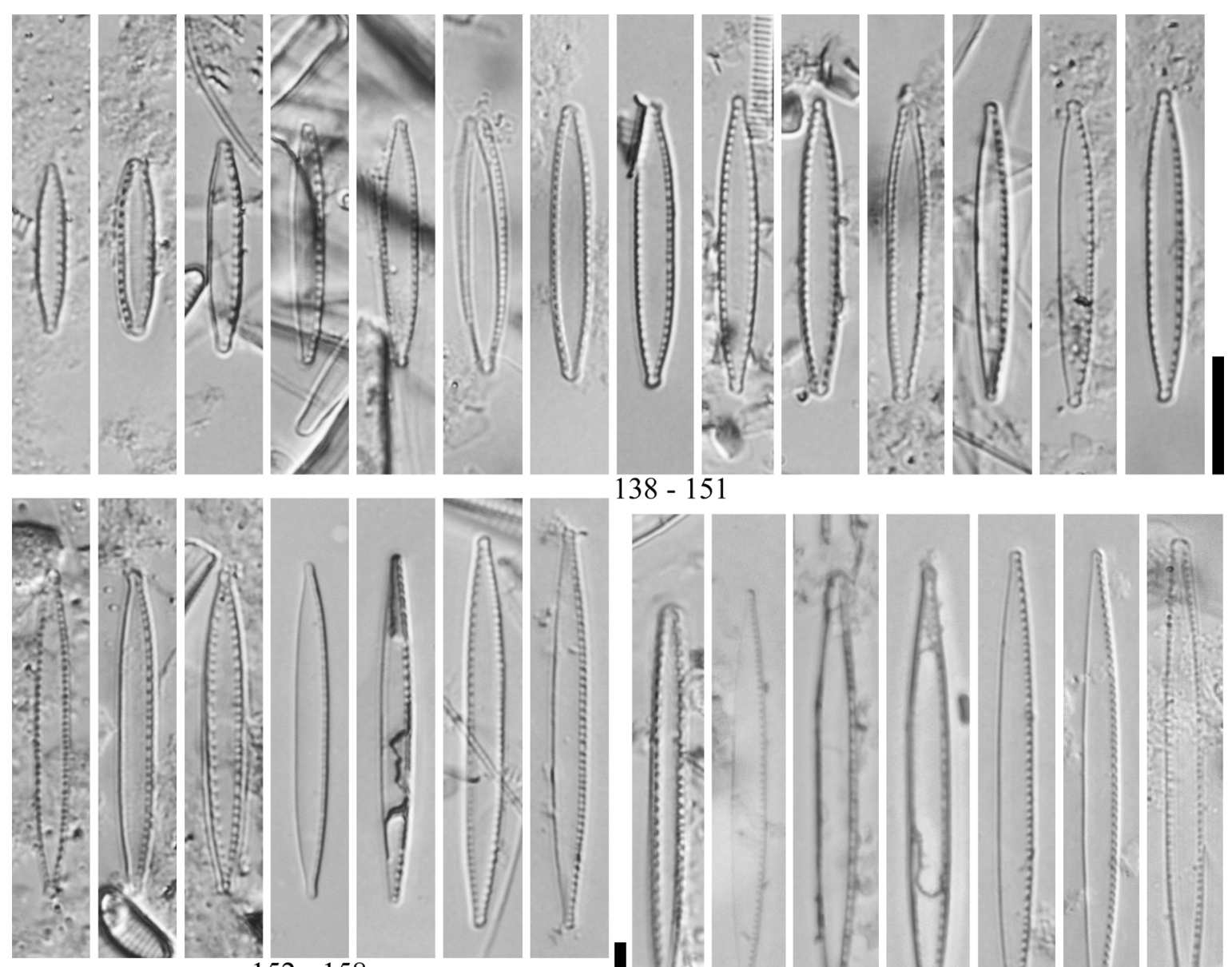

$138-151$
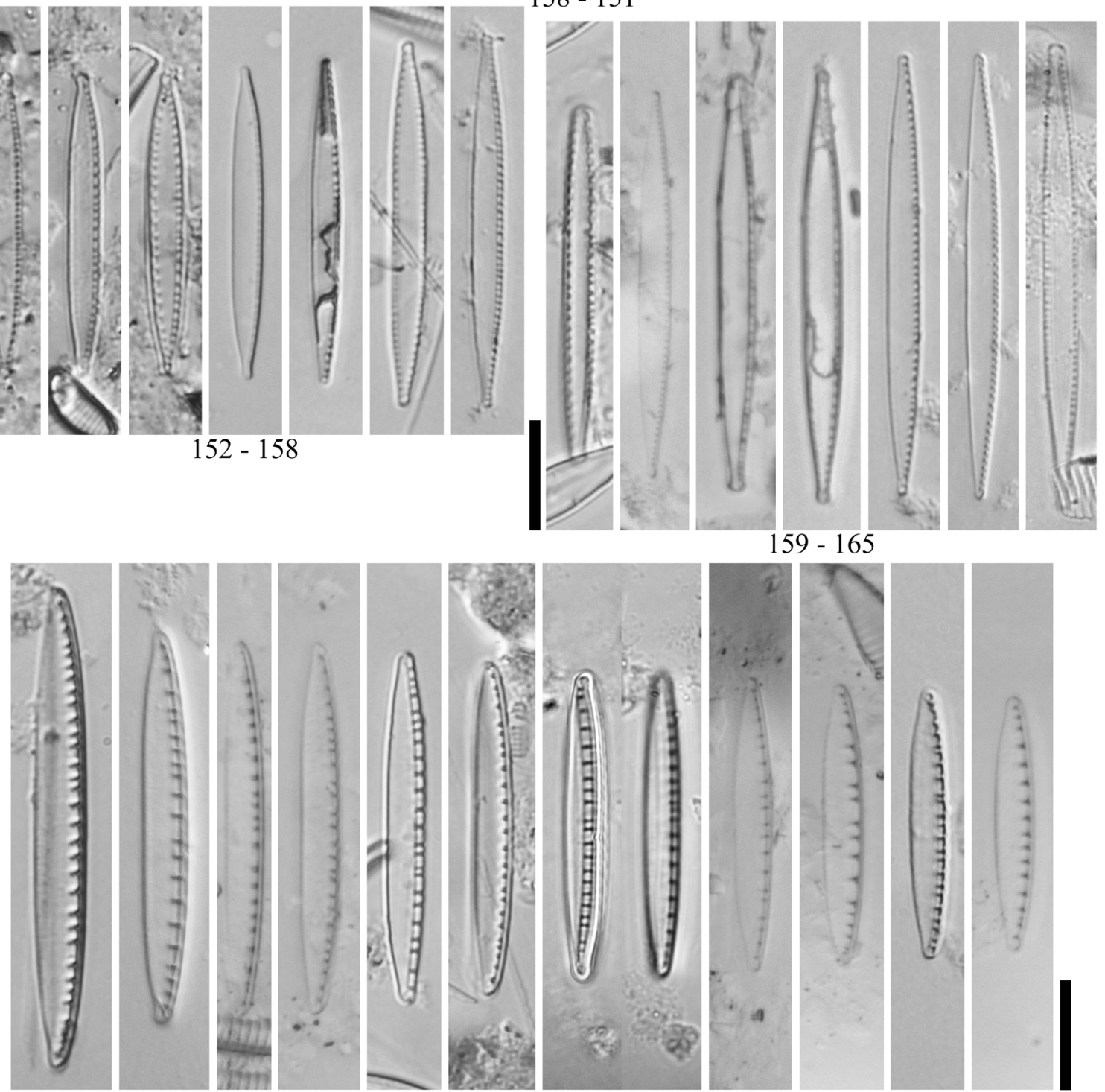

$59-165$

$166-177$

Figuras 138-177. Representantes de Bacillariaceae no Parque Estadual das Fontes do Ipiranga, São Paulo, SP, Brazil. 138-158. Nitzschia palea (Kützing) W. Smith var. debilis (Kützing) Grunow; 159-165. Nitzschia palea (Kützing) W. Smith var. tenuirostris Grunow; 166-177. Nitzschia recta Hantzsch ex Rabenhorst. Barra de escala $=10 \mu \mathrm{m}$.

Figures 138-177. Bacillariaceae representatives in the Parque Estadual das Fontes do Ipiranga, São Paulo, SP, Brazil. 138-158. Nitzschia palea (Kützing) W. Smith var. debilis (Kützing) Grunow; 159-165. Nitzschia palea (Kützing) W. Smith var. tenuirostris Grunow; 166-177. Nitzschia recta Hantzsch ex Rabenhorst. Scale bar $=10 \mu \mathrm{m}$. 
Frústulas simétricas nos planos lateral e apical; face valvar lanceolada, em vista lateral retangular, ápices cuneados; estrias unisseriadas, as mais centrais paralelas entre si, levemente curvadas próximo dos ápices; aréolas elípticas a circular-alongadas, facilmente discerníveis ao microscópio óptico; canal da rafe marginal, fíbulas evidentes, longas, não raro ultrapassando $2 / 3$ da largura da valva, às vezes ocorre um maior espaçamento na região central da valva de alguns exemplares, pois a distribuição das fíbulas é tanto regular quanto irregular; medidas: eixo apical 10-28 $\mu \mathrm{m}$, eixo transapical 3,8-5 $\mu \mathrm{m}$, eixo pervalvar 3,5-7 $\mu \mathrm{m}, 6-9$ fíbulas em $10 \mu \mathrm{m}, 16-20$ estrias em $10 \mu \mathrm{m}$, 12-16 aréolas em $10 \mu \mathrm{m}$.

Material examinado: BRASIL. São Paulo: São Paulo, Parque Estadual das Fontes do Ipiranga, Jardim Botânico, Lago dos Bugios, 18-VII-1991, D.C. Bicudo, T.A.V. Ludwig \& D.M. Figueiredo (SP255748); 07-XI1996, D.C. Bicudo \& L.L. Morandi (SP294902); córrego Pirarungáua, 18-VII-1991, D.C. Bicudo, T.A.V. Ludwig \& D.M. Figueiredo (SP255749, SP255750); Lago das Garças, 18-VII-1991, D.C. Bicudo, T.A.V. Ludwig \& D.M. Figueiredo (SP255752); Lago das Ninfeias, 07-XI-1996, D.C. Bicudo \& L.L. Morandi (SP294899, SP294900); 24IX-2014, L.F. Costa \& D.C. Bicudo (SP469315, SP469316, SP469317, SP469318); 12-IV-2017, S.A. Oliveira, K.S. Morais \& C.E.M. Bicudo (SP469783); sedimentos, 24IX-2014, L.F. Costa \& D.C. Bicudo (SP469576); Lago do Monjolo, 01-III-1997, D.C. Bicudo, T.A.V. Ludwig \& L.L. Morandi (SP294909); hidrofitotério, 07-VI-2011, P.D.A. Silva, G.C. Marquardt, S.W. Ribeiro \& B. Pelegrini (SP427343); material sobre musgos e tronco de árvore, 07-VI-2011, P.D.A. Silva, G.C. Marquardt, S.W. Ribeiro \& B. Pelegrini (SP427344).

Neste estudo, as populações de $N$. amphibia e $N$. semirobusta assemelharam-se nas medidas lineares, havendo forte sobreposição nos casos dos eixos apical e transapical e nas densidades de fíbulas, estrias e aréolas. Mas, as espécies puderam ser diferenciadas morfologicamente, pois em N. amphibia as valvas são lanceoladas ou as margens são paralelas, os ápices rostrados a arredondados, a distribuição das fíbulas sempre regular e as fíbulas são cuneadas, curtas ou retangulares, às vezes parecendo raiz de dente.

* Nitzschia subacicularis Hustedt in Schmidt, Atlas der Diatomaceen-Kunde. 87, pl. 348, fig. 76. 1921.

Figuras 189-204

Frústulas simétricas nos planos lateral e apical, simetria nitzschioide; face valvar lanceolada a fusiforme, ápices afilados; estrias paralelas; aréolas inconspícuas ao microscópio óptico; canal da rafe marginal, fíbulas curtas, distribuídas regularmente, sem maior espaçamento das centrais; medidas: eixo apical $19-47 \mu \mathrm{m}$, eixo transapical 2-3 $\mu \mathrm{m}, 11-16$ fíbulas em $10 \mu \mathrm{m}, 24-31$ estrias em $10 \mu \mathrm{m}$.

Material examinado: BRASIL. São Paulo: São Paulo, Parque Estadual das Fontes do Ipiranga, Jardim Botânico, Lago das Garças, 18-VII-1991, D.C. Bicudo, T.A.V. Ludwig \& D.M. Figueiredo (SP255751); 14-I-1997, D.C. Bicudo \& L.L. Morandi (SP294904, SP294905); hidrofitotério,
07-VI-2011, P.D.A. Silva, G.C. Marquardt, S.W. Ribeiro \& B. Pelegrini (SP427341, SP427342).

Nitzschia terrestris (Petersen) Hustedt, Abhandlungen und Vorträgen der Bremer Wissenschaftlichen Gesellschaft 8-9: 396. 1934 =Nitzschia vermicularis (Kützing) Hantzsch var. terrestris Petersen in Rosenvinge \& Warming, The Botany of Iceland 2(2): 418, fig. 21. 1928.

Figuras 205-207

Frústulas simétricas no plano lateral, às vezes pouco sigmoides nas extremidades, margens levemente côncavas no centro, simetria hantzschioide, ápices rostrados; estrias e aréolas inconspícuas ao microscópio óptico; canal da rafe marginal, apenas em uma das margens; fíbulas retangulares, distribuídas regularmente, curtas, largas, espaçamento entre as fíbulas centrais; medidas: eixo apical 27,5-72,5 $\mu \mathrm{m}$, eixo transapical 4,5-5 $\mu \mathrm{m}, 6-9$ fibulas em $10 \mu \mathrm{m}, 34-35$ estrias em $10 \mu \mathrm{m}$.

Material examinado: BRASIL. São Paulo: São Paulo, Parque Estadual das Fontes do Ipiranga, Jardim Botânico, Lago do Monjolo, 01-III-1997, D.C. Bicudo, T.A.V. Ludwig \& L.L. Morandi (SP294909); hidrofitotério, 07-VI-2011, P.D.A. Silva, G.C. Marquardt, S.W. Ribeiro \& B. Pelegrini (SP427343); 12-IV-2017, S.A. Oliveira, K.S. Morais \& C.E.M. Bicudo (SP469783); Lago das Ninfeias, 07-XI1996, D.C. Bicudo \& L.L. Morandi (SP294899, SP294900); Lago das Ninfeias, brejo, 15-I-1997, D.C. Bicudo \& L.L. Morandi (SP294908); material sobre musgos e tronco de árvore, 07-VI-2011, P.D.A. Silva, G.C. Marquardt, S.W. Ribeiro \& B. Pelegrini (SP427344).

\section{Nitzschia sp. 1}

Figuras 208-210

Frústulas assimétricas no plano lateral; canal da rafe marginal, apenas em uma das margens, margem sem rafe linear-lanceolada, ápices cuneados, largos; estrias paralelas, aréolas inconspícuas, fíbulas evidentes, distribuição regular, muito curtas, retangulares, podem estender-se em geral por até 6 estrias, raro até 13 estrias, maior espaçamento entras as fíbulas centrais; medidas: eixo apical 32-34,5 $\mu \mathrm{m}$, eixo transapical ca. $4 \mu \mathrm{m}, 5-6$ fíbulas em $10 \mu \mathrm{m}, 21-23$ estrias em $10 \mu \mathrm{m}$.

Material examinado: BRASIL. São Paulo: São Paulo, Parque Estadual das Fontes do Ipiranga, Jardim Botânico, Lago dos Bugios, 18-VII-1991, D.C. Bicudo, T.A.V. Ludwig \& D.M. Figueiredo (SP255747); córrego Pirarungáua, 18-VII-1991, D.C. Bicudo, T.A.V. Ludwig \& D.M. Figueiredo (SP255749).

O material ora descrito assemelha-se a $N$. pellucida Grunow no formato das valvas e dos ápices, estrias paralelas, aréolas inconspícuas e espaçamento entre as fíbulas centrais. Nitzschia pellucida difere por apresentar

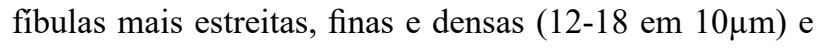
estriação mais densa (30-40 em $10 \mu \mathrm{m})$. Nitzschia pelucida é encontrada, usualmente, em águas salobras e costeiras (Krammer \& Lange-Bertalot 1988).

\section{Nitzschia sp. 2}

Figuras 211-215

Frústulas simétricas no plano apical; valvas linearlanceoladas, laterais paralelas ou sutilmente côncavas, ápices cuneados, estreitos, arredondados; estrias paralelas, 

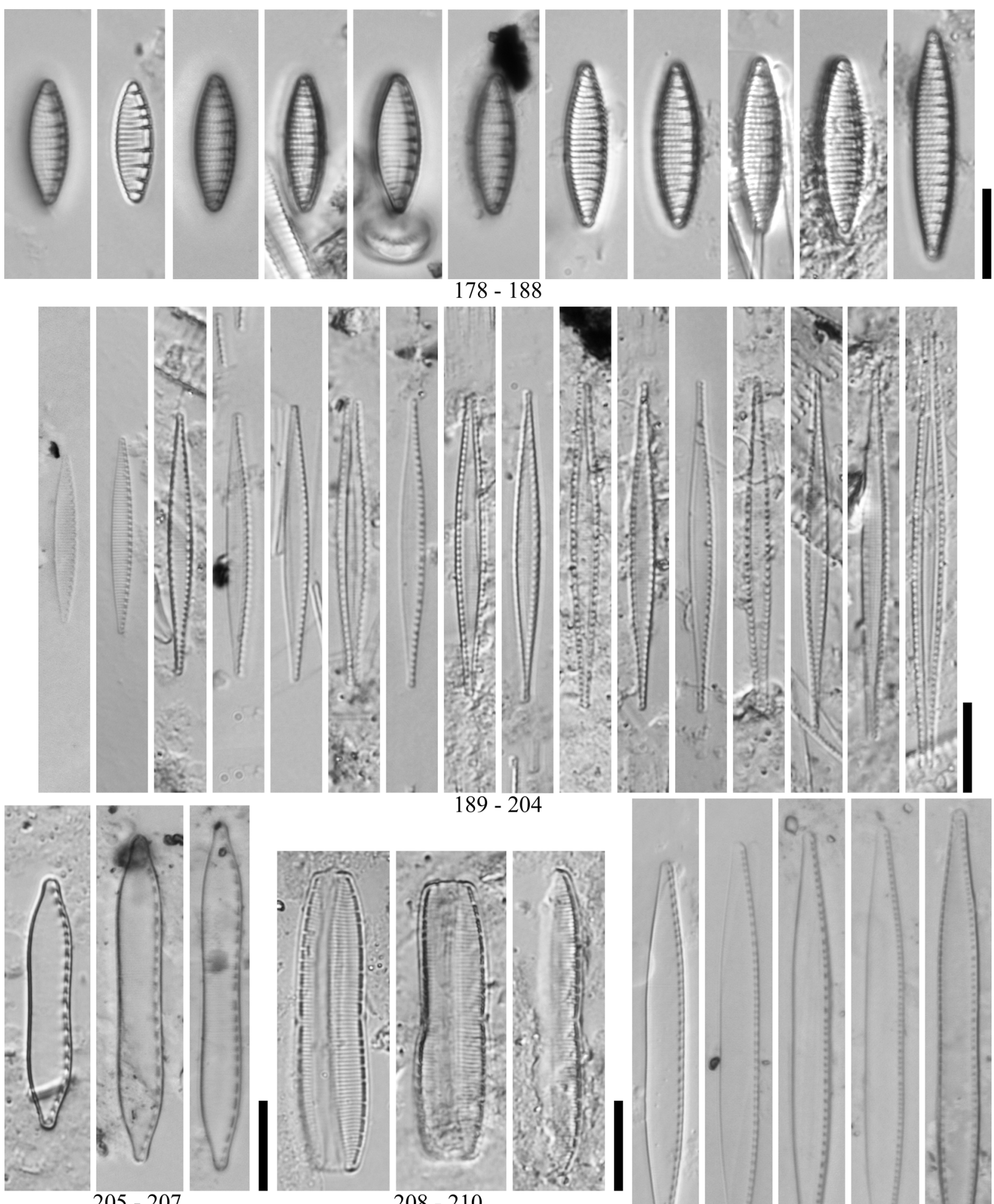

$189-204$

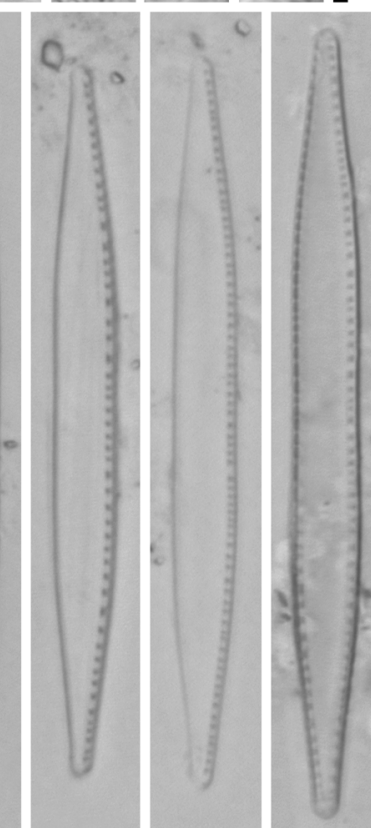

$211-215$

Figuras 178-215. Representantes de Bacillariaceae no Parque Estadual das Fontes do Ipiranga, São Paulo, SP, Brazil. 178-188. Nitzschia semirobusta Lange-Bertalot; 189-204. Nitzschia subacicularis Hustedt; 205-207. Nitzschia terrestris (Petersen) Hustedt; 208-210. Nitzschia sp. 1; $211-215$. Nitzschia sp. 2. Barra de escala $=10 \mu \mathrm{m}$.

Figures 178-215. Bacillariaceae representatives in the Parque Estadual das Fontes do Ipiranga, São Paulo, SP, Brazil. 178-188. Nitzschia semirobusta Lange-Bertalot; 189-204. Nitzschia subacicularis Hustedt; 205-207. Nitzschia terrestris (Petersen) Hustedt; 208-210. Nitzschia sp. 1; $211-215$. Nitzschia sp. 2. Scale bar $=10 \mu \mathrm{m}$. 
às vezes de difícil visualização ao microscópio óptico, aréolas inconspícuas; canal da rafe marginal, fíbulas curtas, distribuição mais ou menos regular, sem maior espaçamento das centrais; medidas: eixo apical 41-55 $\mu \mathrm{m}$, eixo transapical 3,2-4,5 $\mu \mathrm{m}, 10-15$ fíbulas em $10 \mu \mathrm{m}$, ca. 35 estrias em $10 \mu \mathrm{m}$.

Material examinado: BRASIL. São Paulo: São Paulo, Parque Estadual das Fontes do Ipiranga, Jardim Botânico, Lago das Ninfeias, 25-XI-2014, L.F. Costa \& D.C. Bicudo (SP469318); sedimentos, 24-IX-2014, L.F. Costa \& D.C. Bicudo (SP469576); hidrofitotério, 07-VI-2011, P.D.A. Silva, G.C. Marquardt, S.W. Ribeiro \& B. Pelegrini (SP427342); 12-IV-2017, S.A. Oliveira, K.S. Morais \& C.E.M. Bicudo (SP469783).

Representantes deste material foram encontrados anteriormente no reservatório de Barra Bonita com medidas do eixo apical um pouco mais abrangentes $(38,3-62,7 \mu \mathrm{m})$, medidas da largura apresentando sobreposição, porém, com limites maiores $(4-4,7 \mu \mathrm{m})$ e estrias de 10 a $14 \mathrm{em}$ $10 \mu \mathrm{m}$. A morfologia da valva, margens, ápices, fíbulas e estrias são semelhantes (Bartozek et al. 2018). Nitzschia capitelata Hustedt também pode ser comparada com o presente material, pois mostra a mesma forma da valva, morfologia das fíbulas e estrias de difícil visualização. Difere, porém, nos ápices rostrados a capitados e por possuir intervalo nas fíbulas centrais. As medidas dos eixos apical $(20-70 \mu \mathrm{m})$ e transapical $(33,5-6,5 \mu \mathrm{m})$ e a densidade de fíbulas $(10-18 \mathrm{em} 10 \mu \mathrm{m})$ e estrias $(35-40 \mu \mathrm{m})$ são mais abrangentes $N$. capitelata do que nos espécimes encontrados no PEFI (Cantonati et al. 2017).

* Tryblionella debilis Arnott ex O'Meara, Quarterly Journal of Microscopical Science: sér. 2, 13: 310. 1873.

Figuras 216-220

Frústulas simétricas no plano lateral, simetria hantzschioide; valvas elípticas, leve concavidade na região mediana de cada margem, face valvar com ondulações em uma metade, lisa na outra metade, ápices obtusos a arredondados; estrias e aréolas inconspícuas ao microscópio óptico; canal da rafe e fibulas marginais retangulares, distribuídas regularmente, interrompidas no centro da margem; medidas: eixo apical 18$18,5 \mu \mathrm{m}$, eixo transapical 7,4-8 $\mu \mathrm{m}, 10-18$ fíbulas em $10 \mu \mathrm{m}$.

Material examinado: BRASIL. São Paulo: São Paulo, Parque Estadual das Fontes do Ipiranga, Jardim Botânico, hidrofitotério, 07-VI-2011, P.D.A. Silva, G.C. Marquardt, S.W. Ribeiro \& B. Pelegrini (SP427341); 18-VII-1991, D.C. Bicudo, T.A.V. Ludwig \& D.M. Figueiredo (SP255745).

* Tryblionella victoriae Grunow, Verhandlungen der KaiserlichKöniglichen Zoologisch-Botanischen Gesellschaft in Wien 12: 553, pl. 28, fig. 24. 1862.

Figuras 221-223

Frústulas simétricas no plano lateral, simetria hantzschioide; valva linear-elíptica, às vezes suavemente constrita na região
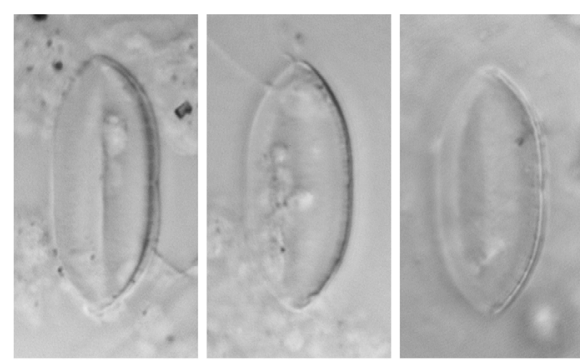

$216-220$
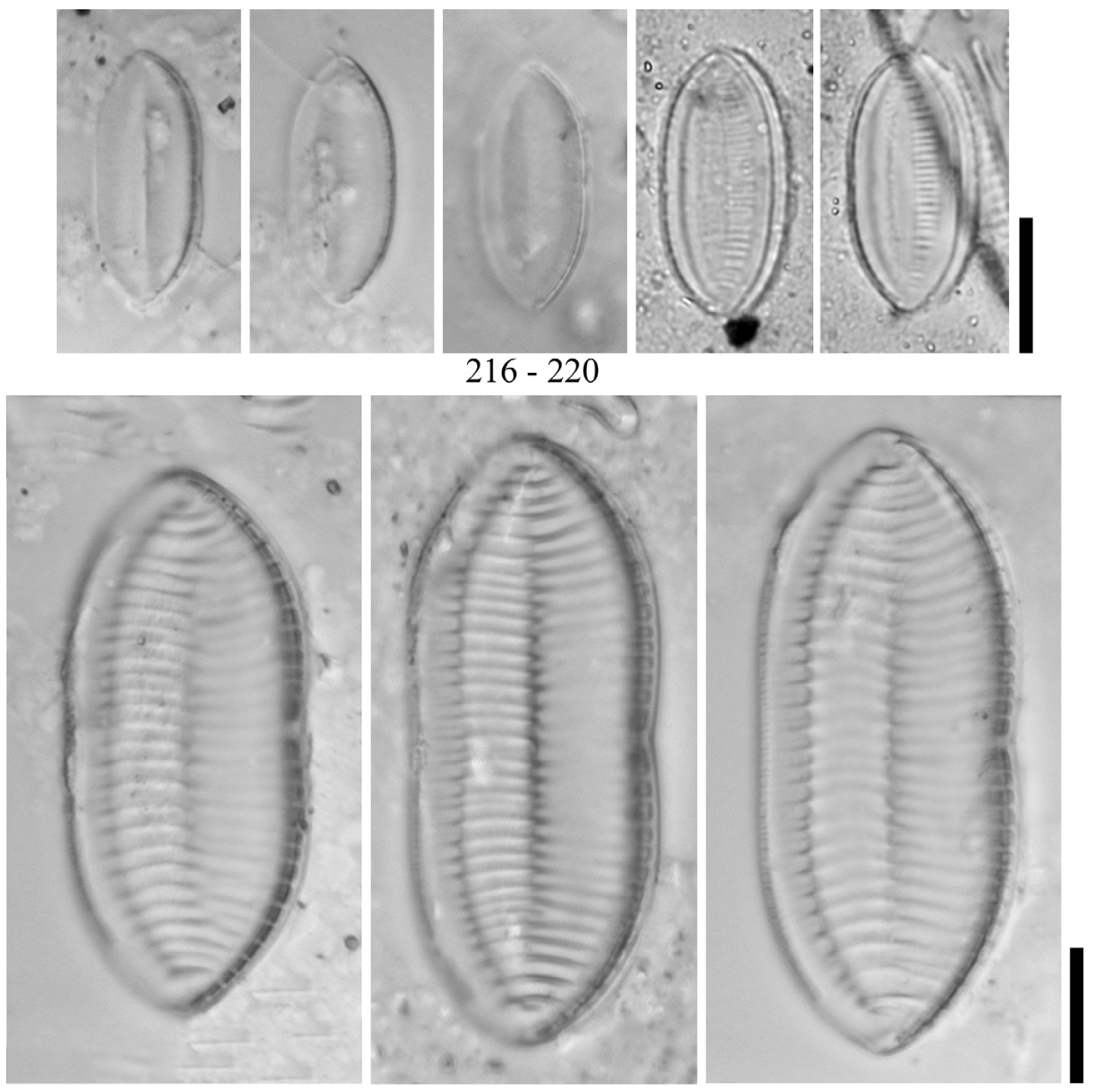

$221-223$

Figuras 216-223. Representantes de Bacillariaceae no Parque Estadual das Fontes do Ipiranga, São Paulo, SP, Brazil. 216-220. Tryblionella debilis Arnott ex O'Meara; 221-223. Tryblionella victoriae Grunow. Barra de escala $=10 \mu \mathrm{m}$.

Figures 216-223. Bacillariaceae representatives in the Parque Estadual das Fontes do Ipiranga, São Paulo, SP, Brazil. 216-220. Tryblionella debilis Arnott ex O’Meara; 221-223. Tryblionella victoriae Grunow. Scale bar $=10 \mu \mathrm{m}$. 
mediana da margem, ápice acuminado-arredondado, face valvar ondulada; estrias e aréolas inconspícuas ao microscópio óptico; costelas onduladas, imbricadas em ziguezague no centro da face valvar; canal da rafe e fíbulas marginais retangulares, distribuídas regularmente, interrompidas no centro da margem; medidas: eixo apical 40-45 $\mu \mathrm{m}$, eixo transapical 18,5-23,5 $\mu \mathrm{m}, 7-8$ fíbulas em $10 \mu \mathrm{m}$.

Material examinado: BRASIL. São Paulo: São Paulo, Parque Estadual das Fontes do Ipiranga, Jardim Botânico, hidrofitotério, 07-VI-2011, P.D.A. Silva, G.C. Marquardt, S.W. Ribeiro \& B. Pelegrini (SP427341, SP427342).

\section{Considerações finais}

O exame de 29 amostras do acervo do Herbário Científico do Estado "Maria Eneyda P. Kauffmann Fidaldo" (SP), do Instituto de Botânica da Secretaria de Infraestrutura e Meio Ambiente do Estado de São Paulo, Brasil, permitiu identificar quatro gêneros e 27 espécies, incluindo cinco variedades taxonômicas. O gênero com maior número de táxons foi Nitzschia com 19 espécies e três variedades não típicas de suas respectivas espécies, seguido por Hantzschia e Tryblionella com duas espécies cada um e Grunowia com apenas uma espécie.

Duas espécies de Nitzschia foram identificadas apenas em nível gênero e o mesmo aconteceu com uma de Hantzschia. Estes materiais possuem características morfológicas diferentes de tudo o que se conhece atualmente sobre seus respectivos gêneros. Suspeita-se tratarem de espécies novas, isto é, ainda não descritas para a Ciência, mas tal decisão só poderá ser tomada após análise de maior número de espécimes e a consequente constatação da assiduidade das características diferenciais em nível populacional. Os locais com maior número de amostras coletadas e estudadas foram o Lago das Ninfeias com sete unidades amostrais e o hidrofitotério com seis. Tais amostras apresentaram também os maiores números de táxons identificados, 12 e 25 , respectivamente.

Oito citações foram consideradas pioneiras para o Estado de São Paulo e são: Nitzschia acicularis Hustedt, $N$. acidoclinata Lange-Bertalot, $N$. clausii Hantzsch, $N$. dissipata (Kützing) Rabenhorst, $N$. intermedia Hantzsch, N. palea (Kützing) W. Smith var. tenuirostris Grunow, N. subacicularis Hustedt, Tryblionella debilis Arnott ex O’Meara e T. victoriae Grunow. Para o Brasil, foram citadas pioneiramente Grunowia solgensis (Cleve-Euler) Aboal e Nitzschia dissipata (Kützing) Rabenhorst var. borneensis Kützing. O presente estudo ampliou, significativamente, a informação sobre a distribuição de representantes da família Bacillariceae nas regiões tropicais.

\section{Agradecimentos}

Os autores agradecem à FAPEAM, Fundação de Amparo à Pesquisa do Estado do Amazonas, pela Bolsa de Doutorado concedida a EAL (Edital n ${ }^{\circ}$ 010/2015 PROPG $\mathrm{AM}$ ); e ao CNPq, Conselho Nacional de Desenvolvimento Científico e Tecnológico, pela Bolsa de Produtividade concedida a CEMB (Processo no $310404 / 2016-9$ ).

\section{Contribuições dos autores}

Elton Augusto Lehmkuhl: Contribuição substancial na concepção, e desenho do estudo; contribuição para coleta de dados; contribuição para a análise e interpretação dos dados; contribuição para a preparação do manuscrito.

Carlos Eduardo de Mattos Bicudo: Contribuição para coleta e interpretação dos dados; contribuição para a preparação do manuscrito. contribuição substancial para revisão crítica, agregando conteúdo intelectual.

\section{Conflitos de interesse}

Não há conflitos de interesse

\section{Literatura citada}

Aboal, M., Álvarez Cobelas, M., Cambra, J. \& Ector, L. 2003. Floristic list of non-marine diatoms (Bacillariophyceae) of Iberian Peninsula, Balearic Islands and Canary Islands: updated taxonomy and bibliography. Diatom Monographs 4: 1-639.

Bartozek, E.C.R., Zorzal-Almeida, S. \& Bicudo, D.C. 2018. Surface sediment and phytoplankton diatoms across a trophic gradient in tropical reservoirs: new records from Brazil and São Paulo State. Hoehnea 45(1): 69-92.

Bertolli, L.M., Talgatti, D.M., Nascimento, T.M.S. \& Torgan, L.C. 2019. Two new species of Tryblionella W. Smith (Bacillariaceae, Bacillariophyta) from a southern Brazil salt marsh. Phytotaxa 399(3): 173-186.

Bertolli, L.M., Talgatti, D.M. \& Torgan, L.C. 2016. Nitzschia papillosa (Bacillariaceae, Bacillariophyta): a new species from a Brazilian salt marsh. Phytotaxa 247(1): 075-084.

Bes, D. \& Torgan, L.C. 2008. O gênero Tryblionella (Bacillariophyta, Bacillariaceae) em ambientes lacustres da planície costeira do Rio Grande do Sul, Brasil. In Anais: Congresso Brasileiro de Ficologia, Simpósio Latino-americano sobre Algas Nocivas, 2006, Itajaí, SC. Aplicações da Ficologia 11: 27-34.

Bes, D. \& Torgan, L.C. 2010a. O gênero Hantzschia Grunow (Nitzschiaceae, Bacillariophyta) em ambientes lacustres na Planície Costeira do Rio Grande do Sul, Brasil. Acta Botanica Brasilica 24(1): 146-152.

Bes, D. \& Torgan, L.C. 2010b. O gênero Nitzschia (Bacillariaceae) em ambientes lacustres na Planície Costeira do Rio Grande do Sul, Brasil. Rodriguesia 61(3): 359-382.

Cantonati, M., Kelly, M.G. \& Lange-Bertalot, H. 2017. Freshwater benthic diatoms of Central Europe: over 800 common species used in ecological assessment. English edition with updated taxonomy and added species. Koeltz Botanical Books, Schmitten-Oberreifenberg.

Cavalcante, K.P., Tremarin, P.I., Freire, E.G. \& Ludwig, T.A.V. 2013. Tryblionella persuadens comb. nov. (Bacillariaceae, Diatomeae): new observations on frustule morphology of a seldom recorded diatom. Anais da Academia Brasileira de Ciências 85(4): 1419-1426. 
Cleve, P.T. \& Grunow, A. 1880. Beiträge zur Kenntniss der arctischen Diatomeen. Kungliga Svenska VetenskapsAkademiens Handlingar 17(2): 1-121.

Cleve-Euler, A. 1952. Die Diatomeen von Schweden und Finnland, 5 (Schluss). Kungliga Svenska VetenskapsAkademiens Handlingar, sér. 4, 3(3): 1-153.

ECS, European Committee for Standartization. 2003. Water quality: guidance standards for the routine sampling and pretreatment of benthic diatoms from rivers. EN 13946. Geneva. 14 p. Disponível em http:// www.safrass. com/partners_area/BSI\%20Benthic $\% 20$ diatoms.pdf (acesso em 17-X-2020).

Ehrenberg, C.G. 1843. Verbreitung und Einfluss des mikroskopischen Lebens in Süd- und NordAmerika. Abhandlungen der Königlichen Akademie der Wissenschaften zu Berlin 1841: 291-466.

Ferreira, K.S.M. \& Bicudo, C.E.M. 2017. Criptógamos do Parque Estadual das Fontes do Ipiranga, São Paulo, SP. Algae, 42: Bacillariophyceae (Surirellales). Hoehnea 44(1): 10-28.

Garcia-Baptista, M. 1993. Observations on genus Hantzschia Grunow at a sandy beach in Rio Grande do Sul, Brazil. Diatom Research 8(1): 31-43.

Grunow, A. 1862. Die Österreichischen Diatomaceen nebst Anschluss einiger neuen Arten von andern Lokalitäten und einer kritischen Uebersicht der bisher bekannten Gattungen und Arten. Verhandlungen der kaiserlichköniglichen zoologisch-botanischen Gesellschaft in Wien 12: 315-472 [Abt 1], 545-588 [Abt. 2], 7 pl.

Guiry, M.D. \& Guiry, G.M. 2019. AlgaeBase: World-wide electronic publication. National University of Ireland, Galway. Disponível em http://www.algaebase.org (acesso em 4-IX-2019).

Hantzsch, C.A. 1860. Neue Bacillarien: Nitzschia vivax var. elongata, Cymatopleura nobilis. Hedwigia 2(7): 1-40.

Hoffmann, G., Werum, M. \& Lange-Bertalot, H. 2013. Diatomeen im Süßwasser-Benthos von Mitteleuropa. Bestimmungs flora Kieselalgen für die ökologische Praxis: über 700 der häufigsten Arten und ihre Ökologie. Koeltz Scientific Books, Königstein.

Hustedt, F. 1934. Die Diatomeenflora von Poggenpohls Moor bei Dötlingen in Oldenburg. Abhandlungen und Vorträgen der Bremer Wissenschaftlichen Gessellschaft 8-9: 362-403.

Kociolek, J.P., Blanco, S., Coste, M., Ector, L., Liu, Y., Karthick, B., Kulikovskiy, M., Lundholm, N., Ludwig, T., Potapova, M., Rimet, F., Sabbe, K., Sala, S., Sar, E., Taylor, J., van de Vijver, B., Wetzel, C.E., Williams, D.M., Witkowski, A. \& Witkowski, J. 2020. DiatomBase. Bacillariaceae Ehrenberg, 1831. World Register of Marine. Disponível em http://www. marinespecies.org/aphia.php? $p=$ taxdetails\&id $=149002$ (acesso em 04-IX-2020).

Krammer, K. \& Lange-Bertalot, H. 1988. Süßwasserflora von Mitteleuropa, 2: Bacillariaceae, Epithemiaceae, Surirellaceae. Gustav Fischer, Stuttgart.

Kützing, F.T. 1844. Die Kieselschaligen Bacillarien oder Diatomeen. W. Köhne, Nordhausen. p. [i-vii], [1]-152.
Lange-Bertalot, H. 1976. Eine Revision zur Taxonomie der Nitzschiae lanceolatae Grunow: Die "klassischen" bis 1930 beschribenen Süsswasserarten Europas. Nova Hedwigia 28: 253-307.

Lange-Bertalot, H. 1993. 85 neue Taxa und über 100 weitere neu definierte Taxa ergänzend zur Süsswasserflora von Mitteleuropa. Bibliotheca Diatomologica 27: 1-164.

Mann, D.G. 1978. Studies in the family Nitzschiaceae (Bacillariophyta). Tese de Doutorado. University of Bristol, Bristol. Disponível em $<$ http:/rbg-web2.rbge. org.uk/algae/publications.refs_mann_tesis_htm $>$ (acesso em 04-IX-2020)

Marquardt, G.C. \& Bicudo, C.E.M. 2014. Criptógamos do Parque Estadual das Fontes do Ipiranga, São Paulo, SP. Algas, 36: Bacillariophyceae (Cymbellales). Hoennea 41(2): 209-246.

Medlin, L.K. \& Kaczmarska, I. 2004. Evolution of diatoms, 5: morphological and cytological support for the major clade and a taxonomy revision. Phycologia 43: $245-270$.

Melhem, T.S., Giulietti, A.M., Forero, E., Barroso, G.M., Silvestre, M.S.F., Jung, S.L., Makino, H., Melo, M.M.R.F., Chiea, S.C., Wanderley, M.G.L., Kirizawa, M. \& Muniz, C. 1981. Planejamento para a elaboração da "Flora Fanerogâmica da Reserva do Parque Estadual das Fontes do Ipiranga (São Paulo, Brasil)". Hoehnea 9: 63-74.

Morais, K.S., Oliveira, S.A., Lehmkuhl, E.A., SilvaLehmkuhl,A.M. \& Bicudo, C.E.M. 2019. Criptógamos do Parque Estadual das Fontes do Ipiranga, São Paulo, SP. Algae, 44: Bacillariophyceae (Surirellales: Epithemia). Hoehnea 46(1): e262018.

Morandi, L.L., Ritter, L.M.O., Moro, R.S. \& Bicudo, C.E.M. 2006. Criptógamos do Parque Estadual das Fontes do Ipiranga, São Paulo, SP. Algas, 20: Coscinodiscophyceae. Hoehnea 33(1): 115-122.

Moreira-Filho, H. \& Valente-Moreira, I.M. 1981. Avaliação taxonômica e ecológica das diatomáceas (Bacillariophyceae) epifíticas em algas pluricelulares obtidas dos litorais do Estado do Paraná, Santa Catarina e São Paulo. Boletim do Museu Botânico Municipal 47: 1-17.

O'Meara, E. 1873. Tryblionella debilis Arnott in Ireland. Quarterly Journal of Microscopical Science, sér. 2, 13: 310.

Petersen, J.B. 1928. The aërial algae of Iceland. In: Rosenvinge, L.K. \& Warming, E. (Eds), The botany of Iceland, 2(2). p. 328-447. Wheldon \& Wesley, Copenhagen \& London.

Rabenhorst, L. 1848-1860. Die Algen Sachsens. Resp. Mittel-Europa's Gesammelt und herausgegeben von Dr. L. Rabenhorst, Dec. 1-100. No 1-1000. [Exsiccatae issued at various dates]. Dresden.

Rabenhorst, L. 1862a. Algen Europa's, Fortsetzung der Algen Sachsens, Resp. Mittel-Europa's. Dec. 31-32. $N^{\circ}$ 1201-1320. Dresden.

Rocha, A.C.R. \& Bicudo, C.E.M. 2008. Criptógamos do Parque Estadual das Fontes do Ipiranga, São Paulo, SP. Algas, 25: Bacillariophyceae (Naviculales: Pinnulariaceae). Hoehnea 35(4): 597-618. 
Round, F.E., Crawford, R.M. \& Mann, D.G. 1990. The Diatoms: biology and morphology of the genera. Cambridge University Press, New York.

Schmidt, A. 1921. Atlas der Diatomaceen-kunde, sér. 8(87): pl. 345-348. O.R. Reisland, Leipzig.

Simonsen, R. 1974. The diatom plankton of the Ocean Expedition of R/V "Meteor", 1964-65 Meteor. Forschungsergebnisse Reihe D-Biologie 19: 1-66.

Smith, W. 1853. A synopsis of the British Diatomaceae; with remarks on their structure, function and distribution; and instructions for collecting and preserving specimens. The plates by Tuffen West. Vol. 1, p. [i]-xxxiii, 1-89, pl. 1-31. John van Voorst, London.

Smith, W. 1856. A synopsis of the British Diatomaceae, with remarks on their structure, functions and distribution; and instructions for collecting and preserving specimens. Vol. 2, p. 1-107, pl. 32-60, 61-62, A-E. John van Voorst, London.

Trobajo, R., Rovira L., Ector L., Wetzel, C.E., Kelly, M. \& Mann, D.G. 2013. Morphology and identity of some ecologically important small Nitzschia species. Diatom Research 1: 1-23.

van Heurck, H. 1880. Synopsis des Diatomées de Belgique, Atlas. Pl. 1-30. Ducaju et Cie, Anvers.

van Heurck, H. 1881. Synopsis des Diatomées de Belgique, Atlas. P1. 31-76. Ducaju et Cie, Anvers.

Recebido: 16.07 .2020

Aceito: 07.01.2021

Editor Associado: Bárbara Dunck Oliveira 